ARTICLE

Check for updates

https://doi.org/10.1038/s41467-021-22394-8

\title{
Efficient photocatalytic hydrogen peroxide generation coupled with selective benzylamine oxidation over defective $\mathrm{ZrS}_{3}$ nanobelts
}

\author{
Zhangliu Tian ${ }^{1,2}$, Cheng Han (10 ${ }^{1 凶}$, Yao Zhao ${ }^{2,3}$, Wenrui Dai ${ }^{2}$, Xu Lian (1) ${ }^{2}$, Yanan Wang ${ }^{4}$, Yue Zheng ${ }^{4}$, Yi Shi (i) ${ }^{2}$, \\ Xuan Pan ${ }^{1,4}$, Zhichao Huang ${ }^{1,4}$, Hexing Li ${ }^{5}$ \& Wei Chen (1) 2,3,4凶
}

Photocatalytic hydrogen peroxide $\left(\mathrm{H}_{2} \mathrm{O}_{2}\right)$ generation represents a promising approach for artificial photosynthesis. However, the sluggish half-reaction of water oxidation significantly limits the efficiency of $\mathrm{H}_{2} \mathrm{O}_{2}$ generation. Here, a benzylamine oxidation with more favorable thermodynamics is employed as the half-reaction to couple with $\mathrm{H}_{2} \mathrm{O}_{2}$ generation in water by using defective zirconium trisulfide $\left(\mathrm{ZrS}_{3}\right)$ nanobelts as a photocatalyst. The $\mathrm{ZrS}_{3}$ nanobelts with disulfide $\left(\mathrm{S}_{2}{ }^{2-}\right)$ and sulfide anion $\left(\mathrm{S}^{2-}\right)$ vacancies exhibit an excellent photocatalytic performance for $\mathrm{H}_{2} \mathrm{O}_{2}$ generation and simultaneous oxidation of benzylamine to benzonitrile with a high selectivity of $>99 \%$. More importantly, the $\mathrm{S}_{2}{ }^{2-}$ and $\mathrm{S}^{2-}$ vacancies can be separately introduced into $\mathrm{ZrS}_{3}$ nanobelts in a controlled manner. The $\mathrm{S}_{2}{ }^{2-}$ vacancies are further revealed to facilitate the separation of photogenerated charge carriers. The $\mathrm{S}^{2-}$ vacancies can significantly improve the electron conduction, hole extraction, and kinetics of benzylamine oxidation. As a result, the use of defective $\mathrm{ZrS}_{3}$ nanobelts yields a high production rate of $78.1 \pm 1.5$ and $32.0 \pm 1.2 \mu \mathrm{mol} \mathrm{h} \mathrm{h}^{-1}$ for $\mathrm{H}_{2} \mathrm{O}_{2}$ and benzonitrile, respectively, under a simulated sunlight irradiation.

\footnotetext{
${ }^{1}$ SZU-NUS Collaborative Innovation Center for Optoelectronic Science \& Technology, International Collaborative Laboratory of 2D Materials for Optoelectronics Science and Technology of Ministry of Education, Institute of Microscale Optoelectronics, Shenzhen University, Shenzhen, China.

2 Department of Chemistry, National University of Singapore, 3 Science Drive 3, Singapore, Singapore. ${ }^{3}$ Joint School of National University of Singapore and Tianjin University, International Campus of Tianjin University, Binhai New City, Fuzhou, China. ${ }^{4}$ Department of Physics, National University of Singapore, 2 Science Drive 3, Singapore, Singapore. ${ }^{5}$ International Joint Lab on Resource Chemistry, College of Chemistry and Materials Science, Shanghai Normal

University, Shanghai, China. ${ }^{凶}$ email: hancheng@szu.edu.cn; phycw@nus.edu.sg
} 
A rtificial photosynthesis, i. e. the conversion of solar energy into chemical energy, is considered as one of the promising approaches to synthesize chemicals with the unlimited energy source and minimized environmental problems ${ }^{1,2}$. As a promising liquid solar fuel generated by artificial photosynthesis, hydrogen peroxide $\left(\mathrm{H}_{2} \mathrm{O}_{2}\right)$ has attracted growing attention because of its high commercial value and low transportation cost ${ }^{3}$. Substantial efforts have been devoted to the development of effective photocatalysts or photocathodes for the $\mathrm{H}_{2} \mathrm{O}_{2}$ generation from water and $\mathrm{O}_{2}{ }^{4-6}$. In the photocatalytic process, the sluggish oxidation of water induced by the photogenerated valence holes is a limiting factor for the production of $\mathrm{H}_{2} \mathrm{O}_{2}{ }^{7-11}$. Most previous reports focused on improving the half-reaction of $\mathrm{O}_{2}$ reduction, e. g. by consuming holes with sacrificial agents, such as isopropyl alcohol, benzyl alcohol, and 2-PrOH $3,12,13$. However, the development of an alternative oxidation reaction with accelerated kinetics to produce value-added chemicals was rarely reported. On the other hand, selective oxidation of amines to nitriles with lower oxidation potential than water plays an vital role in both laboratorial and industrial synthetic process since nitriles are the important intermediates during the synthesis of fine chemicals, pharmaceuticals, and agrochemicals ${ }^{14-21}$. Intensive research has been carried out to synthesize nitriles from primary amines through dehydrogenation ${ }^{22-28}$. However, most of the reactions are conducted in organic solvents under harsh conditions, such as hightemperature, exposure to high-pressure oxygen or air, and presence of oxidants. Photocatalytic reactions have been demonstrated to be an effective approach to synthesize nitriles under mild conditions $^{29-31}$, but previous works were seriously limited by the use of noble metals as the co-catalysts to realize the dehydrogenation in organic solvents. Thus, the development of artificial photosynthesis in an aqueous and easy scale-up condition with earth-abundant photocatalysts is highly desirable for the production of nitriles in an economically-viable and environment-friendly way.

Monoclinic zirconium trisulfide ( $\left.\mathrm{ZrS}_{3}\right)$ (ICCD PDF no. 30-1498), a layered n-type transition metal trichalcogenide (TMT), has recently drawn great research interest due to the extraordinary properties arising from its unique disulfide anions $\left(\mathrm{S}_{2}{ }^{2-}\right)^{32} . \mathrm{ZrS}_{3}$ has shown a good optical responsivity of $290 \mathrm{~mA} \mathrm{~W}^{-1}$ with an inplane hole and electron mobility at a magnitude of $10^{2}$ and $10^{3} \mathrm{~cm}^{2}$ $\mathrm{V}^{-1} \mathrm{~s}^{-1}$, respectively ${ }^{33-36}$. In particular, $\mathrm{ZrS}_{3}$ possesses a bandgap of $\sim 2 \mathrm{eV}$ with a more negative conduction band minimum (CBM) than the $\mathrm{H}_{2}$ evolution potential ${ }^{37}$, making $\mathrm{ZrS}_{3}$ a promising semiconductor for photocatalytic and photoelectrochemical applications. The previous studies on zirconium nitride have demonstrated that its superior performance for $\mathrm{O}_{2}$ reduction stems from the interaction between $\mathrm{Zr}$ sites and oxide species, where the $\mathrm{Zr}$ d-orbitals make a strong contribution ${ }^{38}$. Intriguingly, the conduction band of $\mathrm{ZrS}_{3}$ is mainly composed of $\mathrm{Zr}$ d-orbitals ${ }^{33,35}$, which has a much more negative potential than the reducing potential of $\mathrm{O}_{2}$ to $\mathrm{H}_{2} \mathrm{O}_{2}$. Therefore, $\mathrm{ZrS}_{3}$ shows great potential for the photocatalytic $\mathrm{H}_{2} \mathrm{O}_{2}$ generation.

There are three categories of $S\left(S_{1}, S_{2}\right.$, and $\left.S_{3}\right)$ environments in monoclinic $\mathrm{ZrS}_{3}$ lattice, where $\mathrm{S}_{1}$ denotes the sulfide ion $\left(\mathrm{S}^{2-}\right)$ and $S_{2}, S_{3}$ are interpreted as the $S_{2}{ }^{2-}$ (Fig. 1a, b) ${ }^{39}$. Recently, both theoretical calculations and experimental investigations have demonstrated that moderate $\mathrm{S}_{2}{ }^{2-}$ vacancies can greatly promote the separation of photogenerated charge carriers in TMTs (Supplementary Fig. 1a and b $)^{40,41}$. In addition, the anion vacancies existing on the surface of n-type semiconductors can further improve its photocatalytic and photoelectrochemical performance by accelerating the kinetics of hole transfer on the surface ${ }^{42-45}$. The crystal structure analysis of $\mathrm{ZrS}_{3}$ inspires us that the $\mathrm{S}_{2}{ }^{2-}$ and $\mathrm{S}^{2-}$ vacancies can be separately introduced into $\mathrm{ZrS}_{3}$ by different methods (Fig. 1 and Supplementary Fig. 1). Experimentally, hexagonal $\mathrm{ZrS}_{2}$ (ICCD PDF no. 11-0679) is usually obtained by vacuum annealing of monoclinic $\mathrm{ZrS}_{3}$ at elevated temperatures. This suggests that $\mathrm{ZrS}_{3}$ can desulfurize into $\mathrm{ZrS}_{2}$ by the postannealing at a higher temperature under vacuum ${ }^{46}$. Only one type of $\mathrm{Zr}\left(\mathrm{Zr}_{1}\right)$ and $\mathrm{S}\left(\mathrm{S}_{1}\right)$ environment exists in $\mathrm{ZrS}_{2}$, where the $\mathrm{Zr}_{1}-\mathrm{S}_{1}$ bond length is similar to that in $\mathrm{ZrS}_{3}$ (Fig. 1a-c). Besides, $\mathrm{ZrS}_{2}$ shows a similar layered structure to $\mathrm{ZrS}_{3}$, and atomic layers in both materials are parallel to the (001) plane (Supplementary Fig. 1c-f). When $\mathrm{ZrS}_{3}$ transforms into $\mathrm{ZrS}_{2}$, it does not need much tweaking of the framework along both [010] and [001] directions (Supplementary Fig. 1c and e), but it is required to adjust the framework along the [100] direction (Fig. 1d and f). Figure 1 clearly suggests that the $\mathrm{ZrS}_{3}$ can transform into $\mathrm{ZrS}_{2}$ by two steps: the first step can be the desulfurization of $\mathrm{ZrS}_{3}$ to release $S_{2}$ or $S_{3}$ ions to form a distorted crystal structure of $\mathrm{ZrS}_{2}$ (Fig. 1a, b, d, and e), and then the distorted crystal structure undergoes structural relaxation by tuning the length and angle of $\mathrm{Zr}-\mathrm{S}$ bonds to form $\mathrm{ZrS}_{2}$ without breaking or regrouping the bonds (Fig. 1b, c, e, and f). Thus, the high-temperature vacuum annealing is expected to be an effective scheme to produce $\mathrm{S}_{2}{ }^{2-}$ vacancies in $\mathrm{ZrS}_{3}$. On the other hand, $\mathrm{S}^{2-}$ ions have high adaptability when coordinated with metal ions, which can serve as either terminal or bridge ions to interact with metals (especially for alkali metals). This different from the $S_{x}{ }^{2-}(x \geq 2)$ ions that are difficult to bond with metals (Supplementary Fig. $1 \mathrm{~g})^{47}$. Moreover, $\mathrm{ZrS}_{3}$ is easily formed as nanobelts (NBs) with rich $\mathrm{S}^{2-}$ ions exposed at the edges (Supplementary Fig. 1h and i). Previous studies have used active metals such as $\mathrm{Mg}, \mathrm{Al}$, and $\mathrm{Zn}$ to induce oxygen vacancies in metal oxide due to their reducibility ${ }^{48}$. Compared to these metals, alkali metal lithium (Li) has a higher reducibility and can be easily intercalated into host materials. $\mathrm{Li}$ can be easily dissolved in solvents like ammonia or ethanediamine to form Li-based complex for the solvothermal treatment, which has been widely utilized to enhance the transition temperature of superconducting materials $\mathrm{s}^{49-51}$ and in particular to induce oxygen vacancies on $\mathrm{TiO}_{2}{ }^{52}$. Therefore, such $\mathrm{Li}$-based treatment could be an effective approach to induce $\mathrm{S}^{2-}$ vacancies on $\mathrm{ZrS}_{3}$.

Here, $\mathrm{ZrS}_{3} \mathrm{NBs}$ with both $\mathrm{S}_{2}{ }^{2-}$ and $\mathrm{S}^{2-}$ vacancies are employed to enhance the photocatalytic production of $\mathrm{H}_{2} \mathrm{O}_{2}$ coupled with the selective oxidation of benzylamine to benzonitrile in water. The impacts of $\mathrm{S}_{2}{ }^{2-}$ and $\mathrm{S}^{2-}$ vacancies on modulating the charge carrier dynamics and photocatalytic performance are systematically investigated. The $\mathrm{S}_{2}{ }^{2-}$ vacancies can significantly facilitate the separation of photogenerated charge carriers; while the $\mathrm{S}^{2-}$ vacancies are demonstrated to not only promote the electron conduction and hole extraction in the photocatalytic process but also improve the kinetics of benzylamine oxidation. As a result, the use of defective $\mathrm{ZrS}_{3}$ NBs as photocatalyst produces $\mathrm{H}_{2} \mathrm{O}_{2}$ and benzonitrile at a high rate of $78.1 \pm 1.5$ and $32.0 \pm 1.2 \mu \mathrm{mol} \mathrm{h}^{-1}$ respectively, under the illumination of a simulated sunlight.

\section{Results and discussions}

Structural properties and band structures of photocatalysts. $\mathrm{ZrS}_{3} \mathrm{NBs}$ were synthesized via a chemical vapor transport of S powder to $\mathrm{Zr}$ powder using iodine as a transport agent. $\mathrm{ZrS}_{3}$ with $\mathrm{S}_{2}{ }^{2-}$ vacancies $\left(\mathrm{ZrSS}_{2-\mathrm{x}}\right)$ was obtained by the re-annealing of the as-grown $\mathrm{ZrS}_{3} \mathrm{NBs}$ at $700{ }^{\circ} \mathrm{C}$ for different time $(10,15$, and $20 \mathrm{~min})$ under vacuum. $\mathrm{ZrSS}_{2-\mathrm{x}}$ with $\mathrm{S}^{2-}$ vacancies $\left(\mathrm{ZrS}_{1-\mathrm{y}} \mathrm{S}_{2-\mathrm{x}}\right)$ was prepared through a low-temperature solvothermal treatment by using Li-dissolved ethanediamine with different amounts of $\mathrm{Li}$ $(50,100$, and $150 \mathrm{mg})$. We denote $\mathrm{ZrSS}_{2-\mathrm{x}}$ NBs annealed for $\mathrm{X}$ time as $\mathrm{ZrSS}_{2-\mathrm{x}}(\mathrm{X})$ and $\mathrm{ZrS}_{1-\mathrm{y}} \mathrm{S}_{2-\mathrm{x}} \mathrm{NBs}$ annealed for $\mathrm{X}$ min and treated with $\mathrm{Y}$ mg $\mathrm{Li}$ as $\mathrm{ZrS}_{1-\mathrm{y}} \mathrm{S}_{2-\mathrm{x}}(\mathrm{X} / \mathrm{Y})$. The $\mathrm{x}$-ray diffraction (XRD) pattern indicates the formation of $\mathrm{ZrS}_{3}$ in the monoclinic phase (ICCD PDF no. 30-1498), and the vacuum annealing and 
a

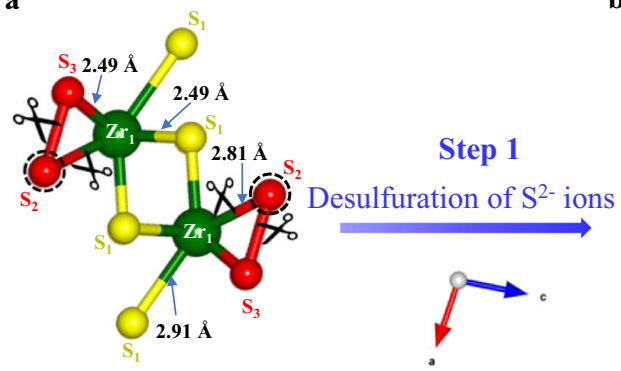

b

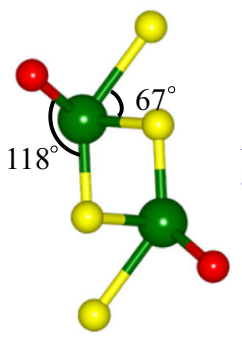

c

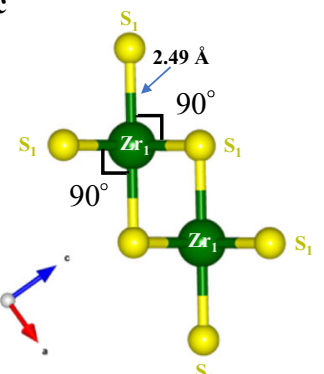

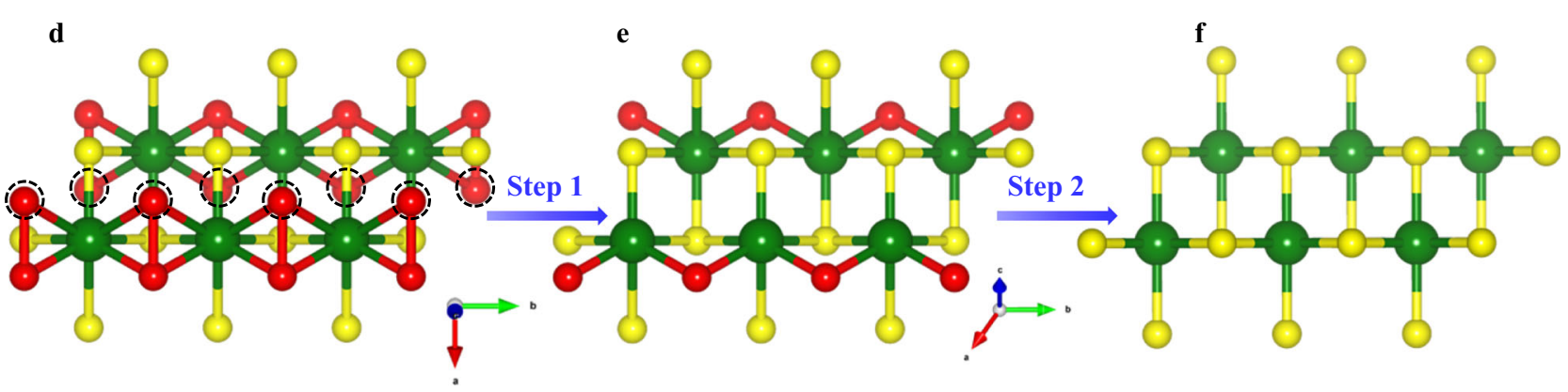

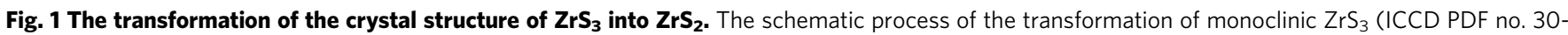
1498) into hexagonal $\mathrm{ZrS}_{2}$ (ICCD PDF no. 11-0679) from the [010] (a-c) and [001] (d-f) views. a, d Crystal structure of monolayer $\mathrm{ZrS} 3$ with a boundary of $1 \times 3 \times 1$ from the [010] and [001] views, respectively. b, e Crystal structure of monolayer $\mathrm{ZrS}_{3}$ after desulfuration of $\mathrm{S}_{2}{ }^{2-}$ ions from a and $\mathbf{d}$, respectively. c, $\mathbf{f}$ Crystal structure of monolayer $\mathrm{ZrS}_{2}$ with a boundary of $1 \times 3 \times 1$ from the [010] and [001] views, respectively.

further $\mathrm{Li}$ treatment did not induce any phase transition in $\mathrm{ZrSS}_{2-\mathrm{x}}(15)$ and $\mathrm{ZrS}_{1-\mathrm{y}} \mathrm{S}_{2-\mathrm{x}}(15 / 100)$ NBs (Supplementary Fig. 2). However, the samples show decreased peak intensity from the $\mathrm{ZrS}_{3}$ to the $\mathrm{ZrS}_{1-\mathrm{y}} \mathrm{S}_{2-\mathrm{x}}(15 / 100) \mathrm{NBs}$, due to the introduction of sulfur vacancies that reduce the crystallinity of $\mathrm{ZrS}_{3}$, as observed in the high-resolution transmission electron microscopy (HRTEM) image (Supplementary Fig. 3). The obtained $\mathrm{ZrS}_{3}$ was formed as NBs with the width ranging from $300 \mathrm{~nm}$ to $3 \mu \mathrm{m}$ and length in tens of micrometers (Fig. 2a-c). Scanning electron microscope (SEM) and atomic force microscope (AFM) measurements were further conducted to statistically determine the length, width, and thickness distribution of $\mathrm{ZrS}_{3}$ NBs. The average length, width, and thickness of NBs were measured to be $24 \mu \mathrm{m}, 840 \mathrm{~nm}$, and $38 \mathrm{~nm}$, respectively (Supplementary Figs. 4 and 5), where all the histograms exhibit a unimodal distribution with the peak in the range of $20-30 \mu \mathrm{m}, 0.6-1.0 \mu \mathrm{m}$ and 25$45 \mathrm{~nm}$, respectively (Supplementary Fig. 4b, c and Supplementary Fig. 5d). As a result, the average ratio of width/thickness was calculated to be $\sim 22$, which qualifies the label of "NBs" for our samples. The individual $\mathrm{ZrS}_{3} \mathrm{NB}$ is confirmed as the single crystal along [010] direction by the TEM and corresponding selected area electron diffraction (SAED) characterization (Fig. 2d). It is demonstrated that the $\mathrm{ZrS}_{3}$ layer is parallel to the axial direction of $\mathrm{NB}$, which is in favor of charge carrier transport ${ }^{40}$. As shown in the HRTEM images (Supplementary Fig. 3), $\mathrm{ZrS}_{3}$ exhibits highly-ordered lattice fringes with an excellent crystallinity, while $\mathrm{ZrS}_{1-y} \mathrm{~S}_{2-\mathrm{x}}(15 / 100)$ shows an obvious lattice disorder with relatively poor crystallinity. This suggests that the introduction of sulfur vacancies could lead to a decreased crystallinity in $\mathrm{ZrS}_{3}$, consistent with the XRD results.

As shown in the diffuse reflectance UV-vis spectra (Fig. 2e), both $\mathrm{ZrS}_{3}$ and $\mathrm{ZrSS}_{2-\mathrm{x}}$ (15) NBs absorb light with the wavelength up to $\sim 650 \mathrm{~nm}$, corresponding to a bandgap of $2.02 \mathrm{eV}$ (Supplementary Fig. 6). $\mathrm{ZrS}_{1-\mathrm{y}} \mathrm{S}_{2-\mathrm{x}}(15 / 100) \mathrm{NBs}$ present a slight red-shift of absorption spectrum, revealing a smaller bandgap of $1.98 \mathrm{eV}$. The Mott-Schottky plots for all three samples exhibit positive slopes, indicating the n-type behavior of $\mathrm{ZrS}_{3}$ (Fig. 2f).
These results were obtained by measuring the photocatalysts deposited on the fluorine-doped tin oxide (FTO) substrate. It is worth noting that the deposition process did not induce any obvious change of the photocatalyst (Supplementary Fig. $7 \mathrm{a}-\mathrm{c}$ ), suggesting that the sample on the FTO substrate measured with the photoelectrochemical set-up is essentially the same photocatalyst. The flat band potentials $\left(E_{\mathrm{fb}}\right)$ of $\mathrm{ZrS}_{3}, \mathrm{ZrSS}_{2-\mathrm{x}}(15)$, and $\mathrm{ZrS}_{1-\mathrm{y}} \mathrm{S}_{2-\mathrm{x}}(15 / 100)$ are estimated to be $-0.10,-0.11$, and $-0.18 \mathrm{~V}$ versus reversible hydrogen electrode $\left(V_{\mathrm{RHE}}\right)$, respectively (Fig. $2 \mathrm{~g}$ and Supplementary Fig. $7 \mathrm{~d}$ ). $E_{\mathrm{fb}}$ is commonly used to estimate the $\mathrm{CBM}$ for a series of n-type semiconductors at the surface in an aqueous environment, which agreed with their theoretically determined values ${ }^{1,44,53-55}$. Previous studies on the energy positions of semiconductors have shown that the CBM of zirconium-based sulfides is very close to their $E_{\mathrm{fb}} 37,54$, and therefore the CBM of $\mathrm{ZrS}_{3}, \mathrm{ZrSS}_{2-\mathrm{x}}(15)$, and $\mathrm{ZrS}_{1-\mathrm{y}} \mathrm{S}_{2-\mathrm{x}}(15 / 100)$ can be directly determined by their $E_{\mathrm{fb}}$. Based on the Mott -Schottky (Fig. 2f, g, and Supplementary Fig. 7d) and UV-vis spectra results, the CBM and valance band maximum (VBM) for $\mathrm{ZrS}_{3}, \mathrm{ZrSS}_{2-\mathrm{x}}(15)$, and $\mathrm{ZrS}_{1-\mathrm{y}} \mathrm{S}_{2-\mathrm{x}}(15 / 100)$ were revealed to be $-0.10,-0.11,-0.18 V_{\text {RHE }}(\mathrm{CBM})$ and $1.92,1.91$, and $1.80 V_{\text {RHE }}$ (VBM), respectively (Fig. $2 \mathrm{~h}$ and Supplementary Fig. 8). The CBMs of $\mathrm{ZrS}_{3}, \mathrm{ZrSS}_{2-\mathrm{x}}(15)$, and $\mathrm{ZrS}_{1-\mathrm{y}} \mathrm{S}_{2-\mathrm{x}}(15 / 100)$ are higher than the potential for two-electron reduction of $\mathrm{O}_{2}$. Previous studies have shown that the oxidation potential of benzylamine lies higher than that of water, and the benzylamine oxidation was thus used to replace oxygen evolution reaction to couple with photocatalytic and electrocatalytic hydrogen evolution reaction $14,17,55,56$. This suggests the $\mathrm{VBM}$ of defective $\mathrm{ZrS}_{3} \mathrm{NBs}$ lying far below the oxidation potential of benzylamine, indicating that these photocatalysts are applicable to the photocatalytic $\mathrm{O}_{2}$ reduction and benzylamine oxidation.

Characterizations of vacancy structure. Four characteristic Raman modes of $\mathrm{ZrS}_{3}$ located at $~ 147,274,315$, and $524 \mathrm{~cm}^{-1}$ were observed in Fig. 3a, which are assigned to the rigid chain vibration (I: $\mathrm{A}_{\mathrm{g}}$ rigid), internal out-of-plane vibrations 

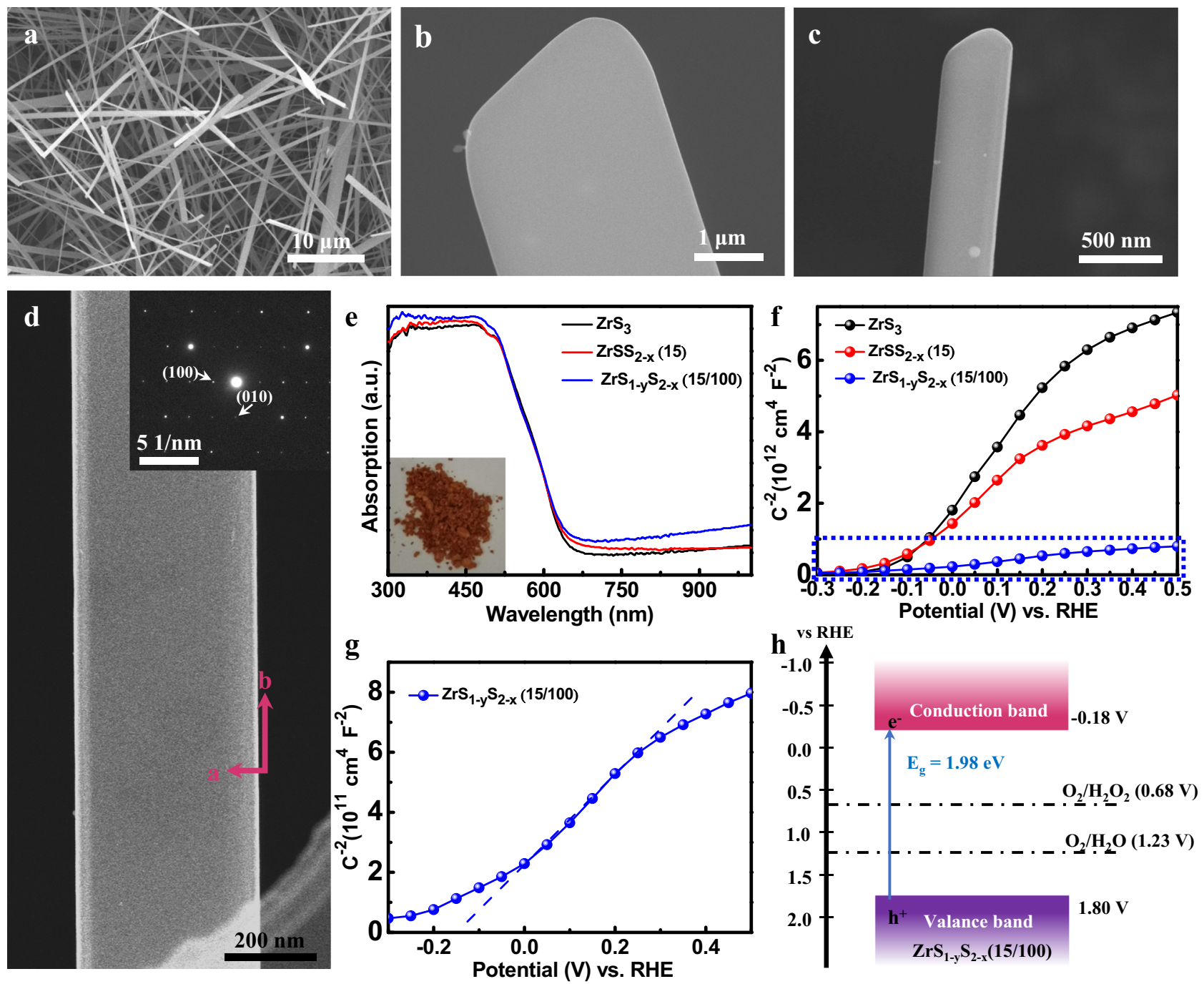

Fig. 2 Structural properties and band structures of defective $\mathbf{Z r S}_{\mathbf{3}} \mathbf{N B s}$. a Top-sectional, $\mathbf{b}$, $\mathbf{c}$ high-magnification SEM images of the ZrS $\mathrm{N}_{3} \mathrm{NBs}$. $\mathbf{d}$ TEM image and SAED pattern of single $Z_{r S}$ NB. e Diffuse reflectance UV-vis spectra of the $Z_{r S} S_{3} Z_{r S S} S_{2-x}(15)$ and $Z r S_{1-y} S_{2-x}(15 / 100) N B s$. Inset, the photograph of the $\mathrm{ZrS}_{1-y} \mathrm{~S}_{2-x}(15 / 100)$ NBs. $\mathbf{f}$ Mott-Schottky plots of $\mathrm{ZrS}_{3}, \mathrm{ZrSS}_{2-x}(15)$ and $\mathrm{ZrS}_{1-y} \mathrm{~S}_{2-x}(15 / 100)$ NBs and $\mathbf{g}$ Mott-Schottky plot of $\mathrm{ZrS} \mathrm{S}_{1-\mathrm{y}} \mathrm{S}_{2-\mathrm{x}}(15 / 100)$ magnified from $\mathbf{f}$. $\mathbf{h}$ Schematic band structure diagram for $\mathrm{ZrS}_{1-y} \mathrm{~S}_{2-x}(15 / 100)$. To have a clear view of the single NB, the sample for this $\mathrm{SEM}$ measurement was prepared by evaporating the isopropanol dispersion of $\mathrm{ZrS}_{3} \mathrm{NBs}$.

(II: $\mathrm{A}_{\mathrm{g}}$ internal and III: $\mathrm{A}_{\mathrm{g}}$ internal), and S-S diatomic motion (IV: $\left.\mathrm{A}_{\mathrm{g}}{ }^{\mathrm{s}-\mathrm{s}}\right)$, respectively ${ }^{35}$. The Raman spectra show an obvious redshift of $\mathrm{A}_{\mathrm{g}}^{\mathrm{s}-\mathrm{s}}$ mode by $\sim 5 \mathrm{~cm}^{-1}$ from $\mathrm{ZrS}_{3}, \mathrm{ZrSS}_{2-\mathrm{x}}(15)$, and $\mathrm{ZrS}_{1-\mathrm{y}} \mathrm{S}_{2-\mathrm{x}}(15 / 100)$, originating from the introduction of $\mathrm{S}_{2}{ }^{2-}$ vacancies ${ }^{40}$. We also observed a $\sim 3 \mathrm{~cm}^{-1}$ red-shift of $\mathrm{A}_{\mathrm{g}}$ rigid mode from $\mathrm{ZrS}_{3}$ and $\mathrm{ZrSS}_{2-\mathrm{x}}(15)$ to $\mathrm{ZrS}_{1-\mathrm{y}} \mathrm{S}_{2-\mathrm{x}}(15 / 100)$. Since the $\mathrm{A}_{\mathrm{g}}$ rigid is correlated to the vibration of quasi-onedimensional chains in the direction of $c$ axis (Supplementary Fig. 9a), the shift of $\mathrm{A}_{\mathrm{g}}$ rigid mode in $\mathrm{ZrS}_{1-\mathrm{y}} \mathrm{S}_{2-\mathrm{x}}(15 / 100)$ results from the introduction of $S^{2-}$ vacancies, which alters the length of $\mathrm{Zr}-\mathrm{S}$ bonds within each chain. The similar shift of $\mathrm{A}_{\mathrm{g}}$ rigid mode was also identified from $\mathrm{ZrS}_{3}$ and $\mathrm{ZrSS}_{2-\mathrm{x}}(15)$ to the only Li-treated $\mathrm{ZrS}_{3}$ with $100 \mathrm{mg} \mathrm{Li}\left(\mathrm{ZrS}_{1-\mathrm{y}} \mathrm{S}(100)\right)$ as shown in Supplementary Fig. 9b. To explore the effect of process parameters during the synthesis of defective materials on the types and density of defects, and the correlation with photocatalytic activity, orthogonal experiments have been performed by simultaneously changing the Li amount and vacuum annealing duration. All the samples were further examined by the Raman characterization, and Supplementary Fig. 10a-d show representative Raman spectra of the defective $\mathrm{ZrS}_{3}$ NBs separately treated by the Li-treatment with different Li amount and by the vacuum annealing for different time. The gradual red-shift of $\mathrm{A}_{\mathrm{g}}$ rigid mode (difference from 1.6 to $6.1 \mathrm{~cm}^{-1}$ ) was observed with increasing $\mathrm{Li}$ amount, resulting from the increased concentration of $\mathrm{S}^{2-}$ vacancies in Li-treated $\mathrm{ZrS}_{3}$ NBs (Supplementary Fig. 10a and b). Similarly, the vacuum annealing triggered a red-shift of $\mathrm{A}_{\mathrm{g}}{ }^{\mathrm{s}-\mathrm{s}}$ mode due to the generated $\mathrm{S}_{2}{ }^{2-}$ vacancies ${ }^{40}$, which was enlarged from 2.4 to $8.1 \mathrm{~cm}^{-1}$ by prolonging the annealing time (Supplementary Fig. 10c and d). Based on the Raman results, the shifts of both $\mathrm{A}_{\mathrm{g}}$ rigid and $\mathrm{A}_{\mathrm{g}} \mathrm{s}$-s modes for all the samples were extracted and plotted as $3 \mathrm{D}$ histograms, as shown in Supplementary Figure 11a and b. The $\mathrm{A}_{\mathrm{g}}$ rigid shift only depends on the $\mathrm{Li}$ amount, while the $\mathrm{A}_{\mathrm{g}} \mathrm{s}$-s shift only relies on the annealing time. These results reveal that the $\mathrm{S}_{2}{ }^{2-}$ and $\mathrm{S}^{2-}$ vacancies in $\mathrm{ZrS}_{1-\mathrm{y}} \mathrm{S}_{2-\mathrm{x}}$ can be independently induced by the vacuum annealing and Li-treatment respectively, and the concentration of vacancies can be further controlled by varying the annealing time and Li amount.

The XPS characterization was conducted on these samples to further confirm the vacancy type. After the vacuum annealing, the $\mathrm{ZrSS}_{2-\mathrm{x}}(15) \mathrm{NBs}$ exhibit a slightly lower binding energy of the 

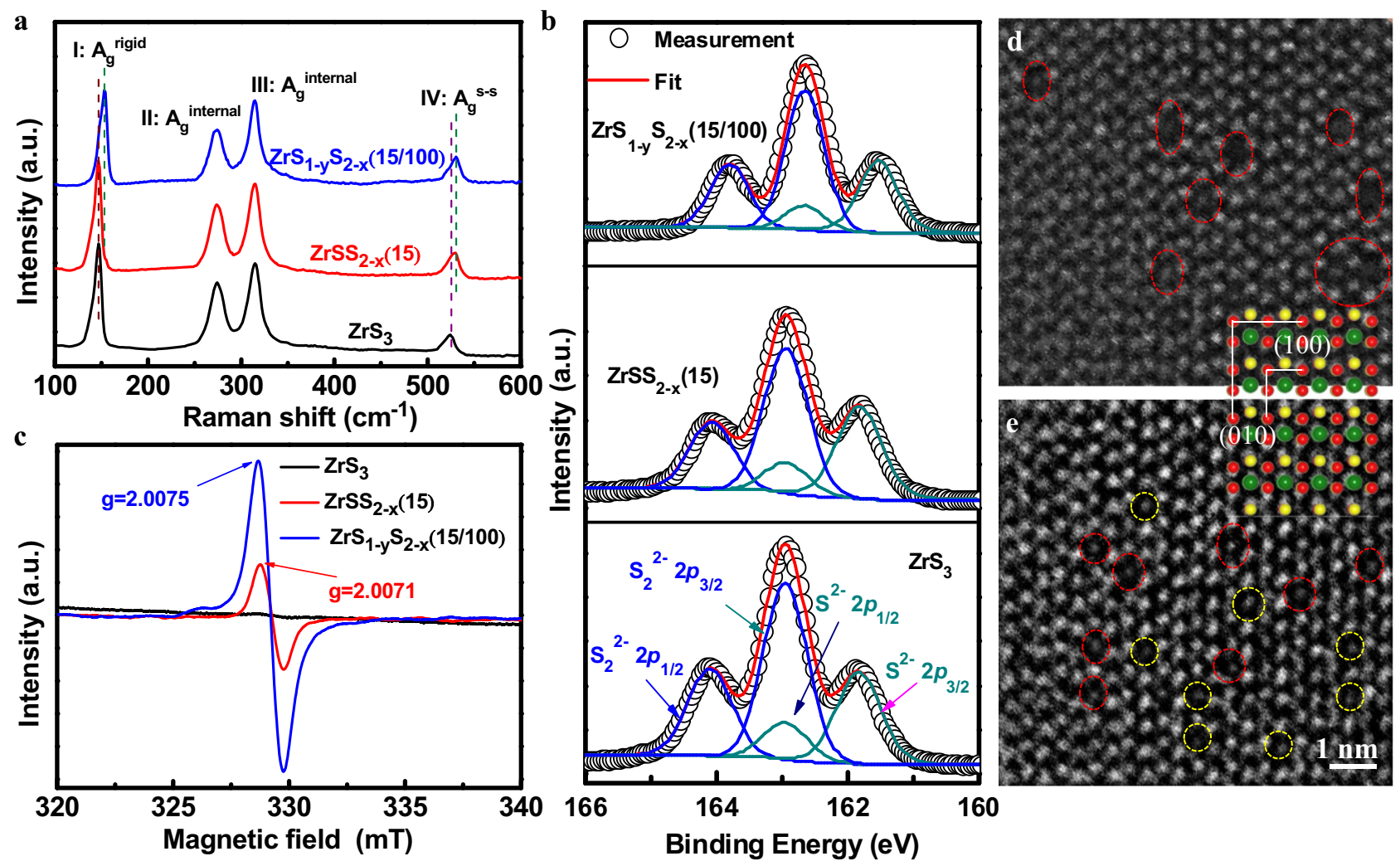

Fig. 3 Characterizations of vacancy structure of defective $\mathbf{Z r S}_{\mathbf{3}} \mathbf{N B s}$. a Raman spectra, $\mathbf{b} \mathrm{S} 2 p \mathrm{XPS}$ spectra, and $\mathbf{c} \mathrm{EPR}_{\mathrm{spectra}}$ of the ZrS $\mathrm{ZrSS}_{2-x}(15)$ and $\mathrm{ZrS}_{1-y} \mathrm{~S}_{2-x}(15 / 100) \mathrm{NBs}$. HAADF-STEM images of $\mathbf{d} \mathrm{ZrSS}_{2-x}(15)$ and $\mathbf{e} \mathrm{ZrS}_{1-y} \mathrm{~S}_{2-x}(15 / 100)$ measured from a spherical aberration-corrected TEM. Inset: the crystal lattice of $\mathrm{ZrS}_{3}$ along the [001] orientation. The red and yellow circles represent $\mathrm{S}_{2}{ }^{2-}$ and $\mathrm{S}^{2-}$, respectively.

$\mathrm{Zr} 3 d$ core level than $\mathrm{ZrS}_{3} \mathrm{NBs}$, consistent with the results from $\mathrm{ZrS}_{3}$ to $\mathrm{ZrS}_{2}$ (Supplementary Fig. 12a) ${ }^{57}$. Furthermore, $\mathrm{ZrSS}_{2-\mathrm{x}}(15)$ shows a significant attenuation of $\mathrm{S}_{2}{ }^{2-} 2 p$ peaks with the nearly unchanged $\mathrm{S}^{2-} 2 p$ peaks compared to $\mathrm{ZrS}_{3}$ (Fig. $3 \mathrm{~b}$ and Supplementary Fig. 12b), indicating the mere increase of $\mathrm{S}_{2}{ }^{2-}$ vacancies in $\mathrm{ZrSS}_{2-\mathrm{x}}(15)$. It is worth noting that no clear peak shift was observed for $\mathrm{ZrSS}_{2-\mathrm{x}}(15)$, which results from the almost retained electron density around the $S$ sites, as revealed by the Mott-Schotty results. After further Li treatment, both $\mathrm{Zr} 3 d$ and S $2 p$ core levels of $\mathrm{ZrS}_{1-\mathrm{y}} \mathrm{S}_{2-\mathrm{x}}(15 / 100) \mathrm{NBs}$ shifted to the lower binding energy by $\sim 0.3 \mathrm{eV}$ regarding $\mathrm{ZrSS}_{2-\mathrm{x}}(15)$ (Supplementary Fig. 12a, c, and d), due to the increased electron density around the $\mathrm{S}$ sites induced by $\mathrm{S}^{2-}$ vacancies $^{58}$. In particular, the intensity of $\mathrm{S}^{2-} 2 p$ peaks in the $\mathrm{ZrS}_{1-\mathrm{y}} \mathrm{S}_{2-\mathrm{x}}(15 / 100)$ was clearly lower than that of $\mathrm{ZrSS}_{2-\mathrm{x}}(15)$ (Fig. 3b and Supplementary Fig. 12d), revealing the increase of $S^{2-}$ vacancies. This phenomenon has been commonly observed in the transition metal sulfide with $\mathrm{S}^{2-}$ vacancies such as $\operatorname{MoS}_{2}, \operatorname{In}_{2} \mathrm{~S}_{3}$, and $\mathrm{CuInS}_{2}{ }^{59-61}$. The similar variation of $\mathrm{Zr} 3 d$ and S $2 p$ spectra observed from $\mathrm{ZrS}_{3}$ to $\mathrm{ZrS}_{1-\mathrm{y}} \mathrm{S}$ (100) further suggest the separate introduction of $S^{2-}$ vacancies by the Li treatment (Supplementary Fig. 12a and c). The type and density of sulfur vacancies for all the samples were further quantitatively analyzed by the XPS characterization, and representative $S 2 p$ XPS spectra of the defective $\mathrm{ZrS}_{3}$ NBs separately treated by the vacuum annealing and Li-treatment are presented in Supplementary Fig. 13a and b, respectively. The $x$ and $y$ values in the label of $\mathrm{ZrS}_{1-\mathrm{y}} \mathrm{S}_{2-\mathrm{x}}$ for all the samples were estimated from the XPS results by calculating the area ratio of characteristic peaks in defective samples to that of $\mathrm{ZrS}_{3}$, as summarized in Supplementary Table 1. Agreed with the Raman results, the vacuum annealing and Li-treatment can independently attenuate the intensity of $\mathrm{S}_{2}{ }^{2-} 2 p$ and $\mathrm{S}^{2-} 2 p$ peaks, respectively, as revealed by the almost unchanged $\mathrm{x}$ and $\mathrm{y}$ values under the identical annealing time and $\mathrm{Li}$ amount, respectively. For an intuitive comparison, the $\mathrm{x}$ and $\mathrm{y}$ values as a function of the annealing time and Li amount were plotted in 3D histograms, as shown in Supplementary Fig. 14a and b, respectively. The $\mathrm{x}$ was estimated to be $0.20 \pm 0.01,0.36 \pm 0.01$, and $0.49 \pm 0.01$ for the annealing time of 10,15 , and $20 \mathrm{~min}$, respectively; while the $y$ was evaluated to be $0.05 \pm 0.01,0.36 \pm 0.01$, and $0.49 \pm 0.01$ for 50,100 , and $150 \mathrm{mg} \mathrm{Li}$, respectively.

In addition, the electron paramagnetic resonances (EPR) investigation was also carried out to detect the vacancy structure. A characteristic peak can be clearly detected at $\mathrm{g}=2.0071$ for all the vacuum annealed samples in Supplementary Fig. 15a, and the peak intensity is proportional to the vacuum annealing duration. This suggested the characteristic peak of $\mathrm{Zr}_{-} \mathrm{S}_{2}{ }^{2-}$ dangling bonds is located at $\mathrm{g}=2.0071^{58}$. Similarly, the characteristic peak of $\mathrm{Zr}-\mathrm{S}^{2-}$ dangling bonds is located at $\mathrm{g}=2.0082$ (Supplementary Fig. 15b). Therefore, the characteristic peak located at $g=2.0075$ for $\mathrm{ZrS}_{1-\mathrm{y}} \mathrm{S}_{2-\mathrm{x}}(15 / 100) \mathrm{NBs}$ suggests the formation of both $\mathrm{S}^{2-}$ and $\mathrm{S}_{2}{ }^{2-y}$ vacancies (Fig. 3c). The higher signal intensity of $\mathrm{ZrS}_{1-\mathrm{y}} \mathrm{S}_{2-\mathrm{x}}(15 / 100)$ than that of $\mathrm{ZrSS}_{2-\mathrm{x}}(15)$ indicates more sulfur vacancies existing in $\mathrm{ZrS}_{1-\mathrm{y}} \mathrm{S}_{2-\mathrm{x}}(15 / 100) \mathrm{NBs}^{60}$. To have a direct view of the atomic arrangement for $\mathrm{ZrSS}_{2-\mathrm{x}}(15)$ and $\mathrm{ZrS}_{1-\mathrm{y}} \mathrm{S}_{2-\mathrm{x}}(15 /$ 100) NBs, the high-angle annular dark-field scanning transmission electron microscopy (HAADF-STEM) images were obtained, where the atomic sites can be determined by comparing the HAADF-STEM image with the crystal structure of $\mathrm{ZrS}_{3}$ lattice along the [001] direction (Supplementary Fig. 15c and d). The $\mathrm{ZrSS}_{2-\mathrm{x}}(15)$ demonstrates the missing atoms only emerging on the $\mathrm{S}_{2}^{2-}$ sites, as indicated by the red dashed circles in Fig. 3d, while the atomic vacancies exist on both $\mathrm{S}^{2-}$ (indicated by yellow dashed circles) and $\mathrm{S}_{2}{ }^{2-}$ sites for $\mathrm{ZrS}_{1-\mathrm{y}} \mathrm{S}_{2-\mathrm{x}}(15 / 100)$ (Fig. 3e). 
a
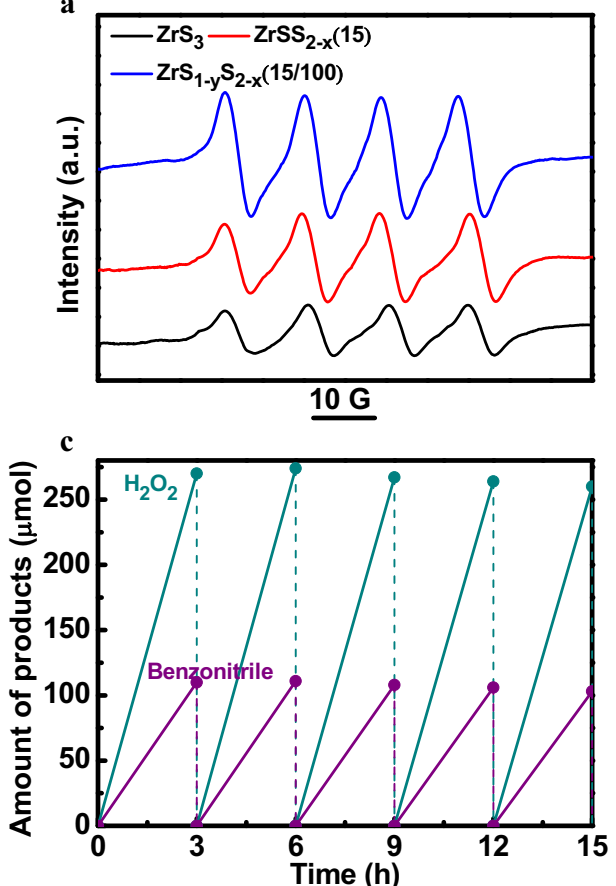

b
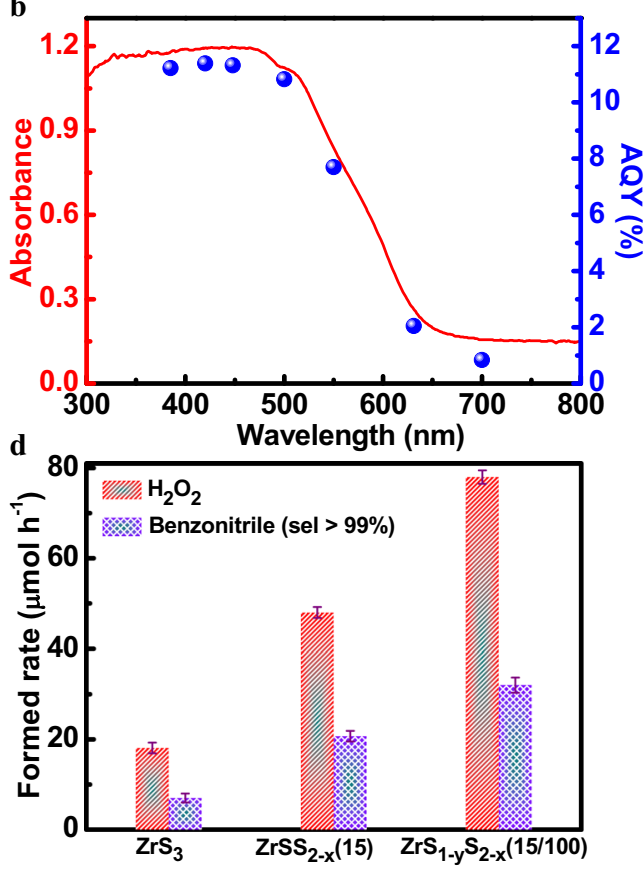

Fig. 4 The photocatalytic properties of defective $\mathbf{Z r S}_{\mathbf{3}}$ NBs. a EPR spectra of $\mathrm{ZrS}_{3}, \mathrm{ZrSS}_{2-x}(15)$ and $\mathrm{ZrS}_{1-y} \mathrm{~S}_{2-x}(15 / 100)$ in the presence of DMPO. b Absorption spectrum of $\mathrm{ZrS}_{1-y} \mathrm{~S}_{2-x}(15 / 100)$ and its dependence of $\mathrm{AQY}$ with monochromatic light irradiation. Conditions: $30 \mathrm{ml}$ aqueous solution with $1 \mathrm{mmol}$ benzyl alcohol, $50 \mathrm{mg}$ photocatalysts. c Results of $\mathrm{H}_{2} \mathrm{O}_{2}$ and benzonitrile generation for a repeated photoreaction sequence with $\mathrm{ZrS}_{1-y} \mathrm{~S}_{2-x}(15 / 100)$ under AM1.5G simulated sunlight irradiation. $\mathbf{d ~} \mathrm{H}_{2} \mathrm{O}_{2}$ and benzonitrile evolution rate by the respective photocatalysts under $\mathrm{AM} 1.5 \mathrm{G}$ simulated sunlight

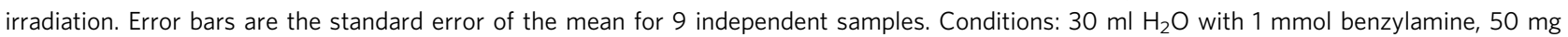
photocatalysts, 1 bar $\mathrm{O}_{2}$.

Photocatalytic performance. The photocatalytic capability of the defective $\mathrm{ZrS}_{3}$ NBs for reducing $\mathrm{O}_{2}$ to create the reactive oxygen species (ROS) was first evaluated by the EPR trapping experiment using 5,5-dimethyl-1-pyrroline N-oxide (DMPO). As illustrated in Fig. 4a, four characteristic peaks of $\mathrm{DMPO}-\mathrm{O}_{2}{ }^{-}-$were observed for all NBs, confirming the generation of $\mathrm{O}_{2}{ }^{\bullet-60,62,63}$. The introduction of $\mathrm{S}_{2}{ }^{2-}$ vacancies was found to enhance the reduction of $\mathrm{O}_{2}$ to $\mathrm{O}_{2}{ }^{--}$, and the additional introduction of $\mathrm{S}^{2-}$ vacancies led to a further increased photocatalytic activity. The correlation of types and density of sulfur vacancies with photocatalytic activity was further examined by the iodometry ${ }^{12}$ under the irradiation of AM1.5G simulated sunlight with the presence of benzyl alcohol as the hole scavenger. As shown in Supplementary Figure 16, the $\mathrm{ZrS}_{1-\mathrm{y}} \mathrm{S}_{2-\mathrm{x}}(15 / 100) \mathrm{NBs}$ with the $\mathrm{x}=0.36$ and $y=0.13(16.3 \%$ sulfur vacancies) exhibit the best performance for photocatalytic $\mathrm{H}_{2} \mathrm{O}_{2}$ generation. When the $\mathrm{Li}$ amount and annealing time were simultaneously less than $150 \mathrm{mg}$ and $20 \mathrm{~min}$, respectively, the photocatalytic activity increased with the increase of both $\mathrm{S}_{2}{ }^{2-}$ and $\mathrm{S}^{2-}$ vacancies. When the $\mathrm{Li}$ amount reached $150 \mathrm{mg}$ or the annealing time reached $20 \mathrm{~min}$, the photocatalytic activity showed an increase at the early stage and then decreased with the increase of annealing time or $\mathrm{Li}$ amount, respectively. This indicates that it is harmful to further improve photocatalytic activity with excessive either $\mathrm{S}_{2}{ }^{2-}$ or $\mathrm{S}^{2-}$ vacancies. This is because excessive sulfur vacancies could act as the recombination centers for photogenerated charge carriers for photogenerated charge carriers. To determine the $\mathrm{H}_{2} \mathrm{O}_{2}$ formed rate, the production was analyzed by iodometry (Supplementary Fig. 17) ${ }^{12}$. The $\mathrm{ZrS}_{1-\mathrm{y}} \mathrm{S}_{2-\mathrm{x}}(15 / 100) \mathrm{NBs}$ possess a high $\mathrm{H}_{2} \mathrm{O}_{2}$ evolution rate of $89.6 \pm 1.5 \mu \mathrm{mol} \mathrm{h}{ }^{-1}$ with good reproducibility (Supplementary Fig. 18) in the presence of benzyl alcohol as the hole scavenger (entry 5 in Supplementary Table 2), which is higher than most previous reports (Supplementary Table 3). The wavelength-dependent apparent quantum yield (AQY) for the $\mathrm{H}_{2} \mathrm{O}_{2}$ generation on $\mathrm{ZrS}_{1-\mathrm{y}} \mathrm{S}_{2-\mathrm{x}}(15 / 100)$ agrees well with its absorption spectrum, revealing that the photocatalytic activity originates from the bandgap excitation of $\mathrm{ZrS}_{1-\mathrm{y}} \mathrm{S}_{2-\mathrm{x}}(15 / 100)$ (Fig. 4b). In particular, $\mathrm{ZrS}_{1-y} \mathrm{~S}_{2-\mathrm{x}}(15 / 100)$ produces an AQY of 11.4 and $10.8 \%$ for the incident light of 400 and $500 \mathrm{~nm}$ respectively and demonstrates a good activity even with the excitation extended to the near-infrared region of $\sim 700 \mathrm{~nm}$. Furthermore, the photocatalyst of $\mathrm{ZrS}_{1-\mathrm{y}} \mathrm{S}_{2-\mathrm{x}}(15 / 100)$ is able to maintain its activity after being recycled for the same reaction with both presence of benzylamine and benzyl alcohol, as presented in Fig. 4c and Supplementary Fig. 19a. After the stability measurement, no noticeable change was observed in the XRD patterns and Raman spectra, revealing good structure stability (Supplementary Fig. 19b and c). In addition, the S $2 p$ XPS spectra of $\mathrm{ZrS}_{1-\mathrm{y}} \mathrm{S}_{2-\mathrm{x}}(15 / 100)$ after the repeated photoreaction show a weak peak located at $\sim 168.7 \mathrm{eV}$ (Supplementary Fig. 19d), suggesting a slight surface oxidation of $\mathrm{ZrS}_{1-y} \mathrm{~S}_{2-\mathrm{x}}(15 / 100)$ after the photocatalytic measurement.

Based on the high activity of $\mathrm{ZrS}_{1-\mathrm{y}} \mathrm{S}_{2-\mathrm{x}}(15 / 100)$ for $\mathrm{H}_{2} \mathrm{O}_{2}$ generation, we further utilized benzylamine to substitute the hole scavenger. The $\mathrm{H}_{2} \mathrm{O}_{2}$ evolution rate of $\mathrm{ZrS}_{1-\mathrm{y}} \mathrm{S}_{2-\mathrm{x}}(15 / 100)$ was decreased to $78.1 \pm 1.5 \mu \mathrm{mol} \mathrm{h}{ }^{-1}$ with the same molar amount of benzylamine as benzyl alcohol, due to the slower oxidation kinetics of benzylamine than that of benzyl alcohol. Simultaneously, the benzylamine was oxidized and converted to benzonitrile at a rate of $32.0 \pm 1.2 \mu \mathrm{mol} \mathrm{h}-1$ with a high selectivity of $>99 \%$ (entry 2 in Supplementary Table 2 and Fig. 4d), and no other by-products were detected by the Gas Chromatography-Mass Spectrometry measurements (Supplementary Fig. 20), consistent with the previous report ${ }^{14,29}$. Besides, the $\mathrm{ZrS}_{1-\mathrm{y}} \mathrm{S}_{2-\mathrm{x}}(15 / 100)$ photocatalyst shows the rates for decomposition of $\mathrm{H}_{2} \mathrm{O}_{2}$ of 0.14 and $0.16 \mathrm{~h}^{-1}$ with the presence of benzyl 
alcohol and benzylamine, respectively, and the rates for formation of $\mathrm{H}_{2} \mathrm{O}_{2}$ of 125 and $113 \mu \mathrm{mol} \mathrm{h}^{-1}$ with the presence of benzyl alcohol and benzylamine, respectively (Supplementary Fig. 17b). Similar photocatalytic behaviors were also identified on both $\mathrm{ZrSS}_{2-\mathrm{x}}(15)$ and $\mathrm{ZrS}_{3} \mathrm{NBs}$, which produced the $\mathrm{H}_{2} \mathrm{O}_{2}$ at a rate of $58.5 \pm 1.7$ and $30.3 \pm 1.3 \mu \mathrm{mol} \mathrm{h}^{-1}$ with the hole scavenger (entry 3 and 1 in Supplementary Table 2), respectively. As a comparison, $\mathrm{ZrSS}_{2-\mathrm{x}}(15)$ and $\mathrm{ZrS}_{3}$ show a decreased $\mathrm{H}_{2} \mathrm{O}_{2}$ evolution rate of $48.0 \pm 1.2$ and $18.1 \pm 1.2 \mu \mathrm{mol} \mathrm{h}^{-1}$ with the use of benzylamine, and the corresponding benzonitrile generation rates are $20.7 \pm 1.2$ and $7.0 \pm 1.0 \mu \mathrm{mol} \mathrm{h} \mathrm{h}^{-1}$, respectively (Fig. $4 \mathrm{~d}$ ). As a result, the comparison of photocatalytic performance among $\mathrm{ZrS}_{1-\mathrm{y}} \mathrm{S}_{2-\mathrm{x}}(15 /$ $100), \mathrm{ZrSS}_{2-\mathrm{x}}(15)$, and $\mathrm{ZrS}_{3}$ reveals the key role of $\mathrm{S}_{2}{ }^{2-}$ and $\mathrm{S}^{2-}$ vacancies on the $\mathrm{O}_{2}$ reduction and benzylamine oxidation.

To provide a deep insight into the effect of defective structures in $\mathrm{ZrS}_{3} \mathrm{NBs}$ on its photocatalytic performance, the transient open-circuit potential measurements were performed on $\mathrm{ZrS}_{3}$, $\mathrm{ZrSS}_{2-\mathrm{x}}(15)$, and $\mathrm{ZrS}_{1-\mathrm{y}} \mathrm{S}_{2-\mathrm{x}}(15 / 100) \mathrm{NBs}$ to reveal the lifetime of photo-induced charge carriers (Supplementary Fig. 21 and Supplementary Equation 4$)^{64}$. After introducing $\mathrm{S}_{2}{ }^{2-}$ vacancies, the carrier lifetime of $\mathrm{ZrSS}_{2-\mathrm{x}}(15)$ was significantly increased to $0.69 \mathrm{~s}$ as compared to $0.3 \mathrm{~s}$ of $\mathrm{ZrS}_{3}$, while the $\mathrm{ZrS}_{1-\mathrm{y}} \mathrm{S}_{2-\mathrm{x}}(15 / 100)$ exhibits a further enhanced lifetime of $0.82 \mathrm{~s}$, as shown in Fig. $5 \mathrm{a}$. The increased photocurrent for the defective $\mathrm{ZrS}_{3}$ also suggests the role of $\mathrm{S}_{2}{ }^{2-}$ and $\mathrm{S}^{2-}$ vacancies on improving the carrier lifetime and dynamics (Supplementary Fig. 22). In order to explore the underlying mechanism for the lifetime enhancement, the charge carrier dynamics of these samples were extracted through the Mott-Schottky method. According to the Mott-Schottky equation (Supplementary Equation 1), the electron concentrations of $\mathrm{ZrS}_{3}, \mathrm{ZrSS}_{2-\mathrm{x}}(15)$, and $\mathrm{ZrS}_{1-\mathrm{y}} \mathrm{S}_{2-\mathrm{x}}(15 / 100) \mathrm{NBs}$ were calculated to be $4.00 \times 10^{18}, 5.35 \times 10^{18}$, and $4.58 \times 10^{19} \mathrm{~cm}^{-3}$, based on the estimated width of the depletion region $\left(\mathrm{w}_{\mathrm{d}}\right)$ under the illumination of 55, 46, and $17 \mathrm{~nm}$, respectively (Supplementary
Equation 2). The similar band bending between $\mathrm{ZrS}_{3}$ and $\mathrm{ZrSS}_{2-\mathrm{x}}(15)$ suggests that the significantly enhanced carrier lifetime in $\mathrm{ZrSS}_{2-\mathrm{x}}(15)$ is attributed to the role of $\mathrm{S}_{2}{ }^{2-}$ vacancies in reducing electron-hole recombination rather than band bending, in agreement with the previous theoretical calculation ${ }^{41}$. The significantly reduced $\mathrm{w}_{\mathrm{d}}$ in $\mathrm{ZrS}_{1-\mathrm{y}} \mathrm{S}_{2-\mathrm{x}}(15 / 100)$ indicates a large electric field strength on the surface of $\mathrm{ZrS}_{1-y} \mathrm{~S}_{2-\mathrm{x}}(15 / 100)$, which can accelerate the extraction of photogenerated holes towards the surface and limit the internal band-to-band recombination. Moreover, the small $\mathrm{w}_{\mathrm{d}}$ in $\mathrm{ZrS}_{1-\mathrm{y}} \mathrm{S}_{2-\mathrm{x}}(15 / 100)$ results in a large conduction region for the free electrons compared to $\mathrm{ZrS}_{3}$ and $\mathrm{ZrSS}_{2-\mathrm{x}}(15)$, which is beneficial for the electron transport.

On the other hand, the reaction kinetics of benzylamine oxidation on the photocatalysts were also investigated by the intensity-modulated photocurrent spectroscopy (IMPS). The typical IMPS plots and the generalized reaction schematics are shown in Supplementary Fig. 23, and the details for the calculation of rate constant of charge transfer $\left(k_{\mathrm{t}}\right)$ and surface recombination $\left(k_{\text {rec }}\right)$ are discussed in the supporting information. Since the $k_{\mathrm{t}} /\left(k_{\mathrm{t}}+k_{\mathrm{rec}}\right)$ can evaluate the efficiency of charge carrier transfer between the catalyst and reactant ${ }^{43}$, the clearly higher $k_{\mathrm{t}} /$ $\left(k_{\mathrm{t}}+k_{\mathrm{rec}}\right)$ of $\mathrm{ZrS}_{1-\mathrm{y}} \mathrm{S}_{2-\mathrm{x}}(15 / 100)$ than those of $\mathrm{ZrSS}_{2-\mathrm{x}}(15)$ and $\mathrm{ZrS}_{3}$ indicates that $\mathrm{ZrS}_{1-\mathrm{y}} \mathrm{S}_{2-\mathrm{x}}(15 / 100)$ possesses higher efficiency for benzylamine oxidation (Fig. 5b). Furthermore, $\mathrm{ZrSS}_{2-x}(15)$ presents a slightly higher $k_{\mathrm{t}} /\left(k_{\mathrm{t}}+k_{\mathrm{rec}}\right)$ compared to $\mathrm{ZrS}_{3}$, as derived from their similar behaviors of $k_{\mathrm{t}}$ and $k_{\text {rec }}$ (Fig. $5 \mathrm{c}$ and d). The similar $k_{\text {rec }}$ between $\mathrm{ZrSS}_{2-\mathrm{x}}(15)$ and $\mathrm{ZrS}_{3}$ is mainly ascribed to their similar surface band bending extracted from the MottSchottky results (Supplementary Fig. $7 \mathrm{~d}$ ). $\mathrm{ZrS}_{1-\mathrm{y}} \mathrm{S}_{2-\mathrm{x}}(15 / 100)$ with the larger surface band bending thus shows a significantly decreased $k_{\text {rec }}$. The slightly decreased $k_{\text {rec }}$ of $\operatorname{ZrSS}_{2-x}(15)$ compared to $\mathrm{ZrS}_{3}$ orginates from the suppression of surface charge recombination by $\mathrm{S}_{2}{ }^{2-}$ vacancies. The similar behavior of $k_{\mathrm{t}}$ for $\mathrm{ZrSS}_{2-\mathrm{x}}(15)$ and $\mathrm{ZrS}_{3}$ indicates that the introduction of $\mathrm{S}_{2}{ }^{2-}$
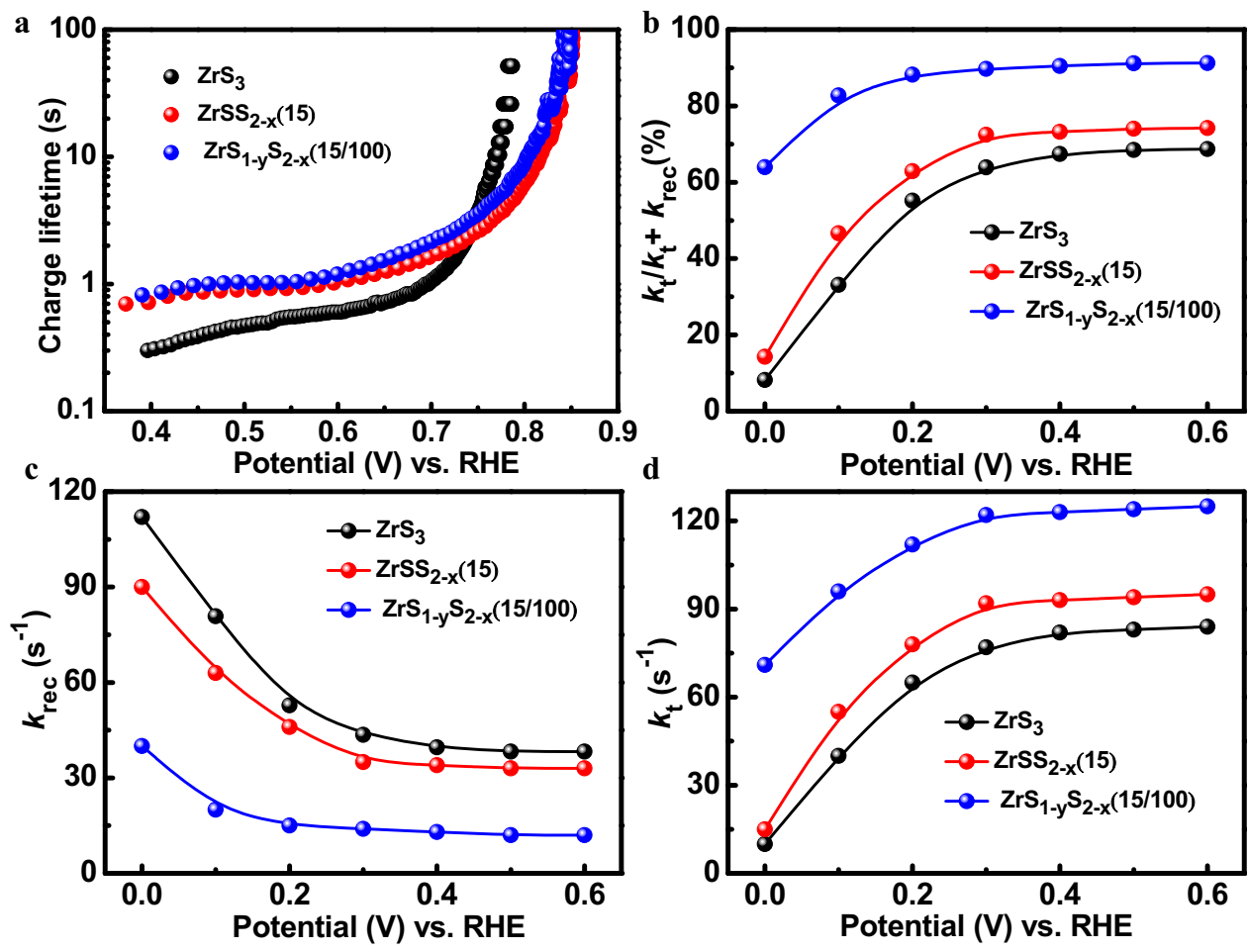

Fig. 5 The charge carrier dynamics of the photocatalysts. a The charge carrier lifetime of $\mathrm{ZrS}_{3}, \mathrm{ZrSS}_{2-\mathrm{x}}(15)$, and $\mathrm{ZrS}_{1-\mathrm{y}} \mathrm{S}_{2-\mathrm{x}}(15 / 100) \mathrm{NBs}$. b Ratio of $k_{\mathrm{t}} /\left(k_{\mathrm{t}}+\right.$ $k_{\text {rec }}$ ), rate constants $\mathbf{c} k_{\mathrm{t}}$ and $\mathbf{d} k_{\text {rec }}$ of $\mathrm{ZrS}_{3}, \mathrm{ZrSS}_{2-\mathrm{x}}(15)$, and $\mathrm{ZrS}_{1-\mathrm{y}} \mathrm{S}_{2-\mathrm{x}}(15 / 100)$ for benzylamine oxidation measured in $0.5 \mathrm{M} \mathrm{Na}_{2} \mathrm{SO}_{4}$ with $0.1 \mathrm{M}$ benzylamine. 
vacancies have a subtle effect on its catalytic capability for benzylamine oxidation. Furthermore, the large increase of $k_{\mathrm{t}}$ for $\mathrm{ZrS}_{1-\mathrm{y}} \mathrm{S}_{2-\mathrm{x}}(15 / 100)$ compared to $\mathrm{ZrSS}_{2-\mathrm{x}}(15)$ and $\mathrm{ZrS}_{3}$ suggests that the $S^{2-}$ vacancies can act as an additional photocatalytic layer for the benzylamine oxidation (Fig. 5d).

In summary, we have developed an efficient photocatalyst of $\mathrm{ZrS}_{1-\mathrm{y}} \mathrm{S}_{2-\mathrm{x}}(15 / 100) \mathrm{NBs}$ with $\mathrm{S}_{2}^{2-}$ and $\mathrm{S}^{2-}$ vacancies for the integration of photocatalytic $\mathrm{H}_{2} \mathrm{O}_{2}$ generation with the selective oxidation of benzylamine to benzonitrile in water. More importantly, the unique $\mathrm{S}_{2}{ }^{2-}$ vacancies and $\mathrm{S}^{2-}$ vacancies can be controllably induced in the defective $\mathrm{ZrS}_{3} \mathrm{NBs}$ by varying the annealing time and $\mathrm{Li}$ amount, which promise a prospective strategy for defect engineering. With the introduction of $\mathrm{S}_{2}{ }^{2-}$ vacancies, the charge carrier recombination is prominently suppressed, and the surface $S^{2-}$ vacancies are revealed to improve the electron conduction, surface hole extraction, and kinetics of benzylamine oxidation. As a result, the photocatalyst of $\mathrm{ZrS}_{1-\mathrm{y}} \mathrm{S}_{2-\mathrm{x}}(15 / 100)$ exhibits a high generation rate of $78.1 \pm$ 1.5 and $32.0 \pm 1.2 \mu \mathrm{mol} \mathrm{h} \mathrm{h}^{-1}$ for $\mathrm{H}_{2} \mathrm{O}_{2}$ and benzonitrile, respectively. Furthermore, $\mathrm{ZrS}_{1-\mathrm{y}} \mathrm{S}_{2-\mathrm{x}}(15 / 100)$ NBs possesses a photoexcitation up to $\sim 700 \mathrm{~nm}$ and delivers a high AQY of 11.4 and $10.8 \%$ under the incident light of 400 and $500 \mathrm{~nm}$, respectively.

\section{Methods}

Preparation of $\mathbf{Z r S}_{\mathbf{3}}, \mathbf{Z r S S}_{\mathbf{2 - \mathbf { x }}}$ and $\mathbf{Z r S}_{\mathbf{1 - y}} \mathbf{S}_{\mathbf{2 - \mathbf { x }}} \mathbf{N B s}$. The $\mathrm{ZrS}_{3}$ NBs were synthesized through a typical chemical vapor transport process. $0.96 \mathrm{~g} \mathrm{~S}$ (99.5\% purity, Alfa Aesar) and $0.91 \mathrm{~g} \mathrm{Zr} \mathrm{(99.2 \%} \mathrm{purity,} \mathrm{Sigma-Aldrich)} \mathrm{powders} \mathrm{were} \mathrm{mixed,}$ and $5 \mathrm{mg}$ iodine $(99.5 \%$ purity, Alfa Aesar) was added as a transport agent. The mixture was sealed in a quartz ampoule $(\Phi 6 \mathrm{~mm} \times 200 \mathrm{~mm})$ under the vacuum of $10^{-3} \mathrm{~Pa}$, which was subsequently placed in the center of a two-zone furnace with a temperature gradient of ca. $15 \mathrm{~K} / \mathrm{cm}$ from center to edge. The furnace was heated to $650{ }^{\circ} \mathrm{C}$ and last for $10 \mathrm{~h}$ to produce $\mathrm{ZrS}_{3}$ powder, which has a pure monoclinic crystal structure that is stable at this temperature. The obtained $1.87 \mathrm{~g} \mathrm{ZrS}_{3}$ powder was then dispersed in isopropanol ( $\geq 99.5 \%$ purity, Alfa Aesar) at a concentration of $0.5 \mathrm{mg} \mathrm{ml}^{-1}$ followed by the sonication for $15 \mathrm{~min}$. The dispersion was subsequently centrifuged for $10 \mathrm{~min}$ at $1006 \mathrm{xg}$ to remove large aggregates. Finally, about $0.6 \mathrm{~g} \mathrm{ZrS}_{3} \mathrm{NBs}$ ( $32 \%$ yield) were obtained by the collection from the rest of the dispersion by further centrifugation for $10 \mathrm{~min}$ at $16099 \mathrm{xg}$.

Since hexagonal $\mathrm{ZrS}_{2}$ (ICCD PDF no. 11-0679) is usually obtained by vacuum annealing of monoclinic $\mathrm{ZrS}_{3}$ at elevated temperature $\left(820^{\circ} \mathrm{C}\right)^{46}$. This suggests that $\mathrm{ZrS}_{3}$ can be desulfurized into $\mathrm{ZrS}_{2}$ by the post-annealing at a higher temperature under vacuum. It is implied that such transformation can also be realized by the desulfuration of $\mathrm{S}_{2}{ }^{2-}$ ions, based on our previous results on $\mathrm{TiS}_{3}$ and crystal structure analysis between $\mathrm{ZrS}_{2}$ and $\mathrm{ZrS}_{3}$ in Fig. 1 and Supplementary Fig. ${ }^{40}$. As a result, the $\mathrm{ZrSS}_{2-\mathrm{x}} \mathrm{NBs}$ were prepared using the previously reported vacuum annealing method. Specifically, $0.6 \mathrm{~g} \mathrm{ZrS}_{3} \mathrm{NBs}$ were sealed in the quartz ampule $(\Phi 6 \mathrm{~mm} \times 10 \mathrm{~mm})$ again, which was then heated to $700{ }^{\circ} \mathrm{C}$ and last for different time $\left(10,15\right.$, and 20 mins) to fabricate $\mathrm{ZrSS}_{2-\mathrm{x}} \mathrm{NBs}$. Besides, a certain amount of $\mathrm{Li}$ metal pieces $(50,100$, and $150 \mathrm{mg}$ ) were added into $30 \mathrm{ml}$ ethanediamine ( $\geq 98 \%$ purity, Sigma-Aldrich) for continuous magnetic stirring in an Ar-filled glovebox $\left(\mathrm{O}_{2}, \mathrm{H}_{2} \mathrm{O}<0.1 \mathrm{ppm}\right)$. After the $\mathrm{Li}$ was completely dissolved, $0.5 \mathrm{~g} \mathrm{ZrSS}{ }_{2-\mathrm{x}} \mathrm{NBs}$ were added into the solution, and the obtained solution was subsequently transferred into a $50 \mathrm{~mL}$ Teflon-lined autoclave and sealed immediately. Then, the Teflonlined autoclave was taken out of the glovebox and kept in an oven at $120{ }^{\circ} \mathrm{C}$ for $24 \mathrm{~h}$. After cooling down to room temperature, the mixture was first washed in $0.2 \mathrm{M} \mathrm{HCl}$ and then rinsed several times in deionized water and ethanol, where the $\mathrm{ZrS}_{1-\mathrm{y}} \mathrm{S}_{2-\mathrm{x}} \mathrm{NBs}$ (yield $>96 \%$ ) was finally obtained.

\section{Characterization of photocatalysts. UV-Vis-NIR spectrometer (Hitachi} U4100), field emission SEM (FE-SEM, JEOL JSM6700F), TEM (FEI Titan 80300 , operated at $200 \mathrm{kV}$ ), XRD (Bruker D8 Advance), XPS (ESCALAB 250Xi) with $\mathrm{Al} \mathrm{Ka} \mathrm{X}$-ray as the excitation source, EPR (JEOL FA200), tapping-mode AFM (MPF-3D, Asylum Research, CA, USA), and Raman spectroscopy (Horiba Jobin Yvon Modular Raman Spectrometer) with $514 \mathrm{~nm}$ laser excitation were employed to characterize different properties of the defective $\mathrm{ZrS}_{3} \mathrm{NBs}$, e.g. atomic and energy band structure. In particular, the samples for the TEM measurements were suspended in ethanol and supported onto a holey carbon film on a $\mathrm{Cu}$ grid.

Coupling photocatalytic $\mathrm{H}_{2} \mathrm{O}_{2}$ generation with selective benzylamine oxidation over $\mathbf{Z r S}_{\mathbf{3}}, \mathbf{Z r S S}_{\mathbf{2 - x}}, \mathbf{Z r S}_{\mathbf{1 - y}} \mathbf{S}_{\mathbf{2}-\mathbf{x}} \mathbf{N B s}$. $50 \mathrm{mg}$ photocatalyst was dispersed in $30 \mathrm{ml} \mathrm{H}_{2} \mathrm{O}$ with $1 \mathrm{mmol}$ benzylamine. After the sonication for a few seconds, the mixed solution was bubbled by oxygen for $30 \mathrm{~s}$. Subsequently, the solution was sealed and irradiated under an AM 1.5G simulated sunlight of $100 \mathrm{~mW} \mathrm{~cm}-2$ derived from a $300 \mathrm{~W}$ xenon lamp fitted with an AM 1.5 filter. At certain time intervals, the solution was filtrated by a $0.22 \mu \mathrm{m}$ Millipore filter to remove the photocatalyst. The aqueous and organic phase products were then analyzed by the iodometry and gas chromatograph (GC) measurements, respectively.

The production of $\mathrm{H}_{2} \mathrm{O}_{2}$ was analyzed by the iodometry ${ }^{12}$. Typically, $50 \mu \mathrm{L}$ $0.4 \mathrm{M}$ potassium iodide (KI, $\geq 99 \%$ purity, Sigma-Aldrich) aqueous solution and $50 \mu \mathrm{L} 0.1 \mathrm{M}$ potassium hydrogen phthalate ( $\geq 99.5 \%$ purity, Sigma-Aldrich) aqueous solution were added to $2 \mathrm{ml}$ obtained aqueous phase product, which was kept for $0.5 \mathrm{~h}$. The mixed solution was then detected by UV-vis spectroscopy on the basis of absorbance at $350 \mathrm{~nm}$, from which the quantity of generated $\mathrm{H}_{2} \mathrm{O}_{2}$ was estimated. In addition, to analyze organic phase product from the benzylamine oxidation, the organic liquid was first extracted using ethyl acetate ( $\geq 99.9 \%$ purity, Sigma-Aldrich) and then detected by the GC characterization. Fihu

Photocatalytic $\mathrm{H}_{\mathbf{2}} \mathrm{O}_{2}$ generation with benzyl alcohol as hole sacrificial reagent. $50 \mathrm{mg}$ catalyst was dispersed in $30 \mathrm{ml} \mathrm{H}_{2} \mathrm{O}$ containing $1 \mathrm{mmol}$ benzyl alcohol. After sonicating for a few seconds, the mixed solution was bubbled by oxygen for few seconds. Subsequently, the solution was sealed and irradiated under an AM 1.5G simulated sunlight of $100 \mathrm{~mW} \mathrm{~cm}^{-2}$ derived from a $300 \mathrm{~W}$ xenon lamp fitted with an AM 1.5 filter. The amount of $\mathrm{H}_{2} \mathrm{O}_{2}$ was analyzed by the iodometry. For the action spectrum analysis, the reactions were performed at $298 \mathrm{~K}$ under monochromated light irradiation, with the $\Phi_{\mathrm{AOY}}$ (AQY, apparent quantum yield) determined by the following Eq. (1):

$$
\phi_{A Q Y}(\%)=\frac{\left[\mathrm{H}_{2} \mathrm{O}_{2} \text { formed }(\mathrm{mol})\right] \times 2}{\text { [photon number entered into the reactor }(\mathrm{mol})]} \times 100
$$

The stability test for $\mathbf{Z r S}_{1-y} \mathbf{S}_{\mathbf{2 - x}} \mathbf{( 1 5 / 1 0 0 )}$ NBs. The the $\mathrm{ZrS}_{1-\mathrm{y}} \mathrm{S}_{2-\mathrm{x}}(15 / 100) \mathrm{NBs}$ was recovered by centrifugation for $15 \mathrm{~min}$ at $16,099 \mathrm{~g}$ and used for the reaction sequence, with water replaced every $3 \mathrm{~h}$ during photoirradiation.

EPR trapping measurements. $4 \mathrm{mg}$ catalyst was suspended in $500 \mu \mathrm{L} \mathrm{CH}_{3} \mathrm{OH}$ containing $50 \mu \mathrm{L}$ DMPO (Sigma-Aldrich for ESR-spectroscopy). After the sonication, the solution was irradiated by a $300 \mathrm{~W}$ xenon lamp with a $420 \mathrm{~nm}$ filter for $3 \mathrm{~min}$. The resulted solution was subjected to the analysis by using a JEOL (FA200) ESR Spectrometer.

Photoelectrochemical measurements. The photoelectrochemical measurements were performed in a three-electrode system with an electrochemical workstation (Zahner Zennium) under an AM 1.5G simulated sunlight of $100 \mathrm{~mW} \mathrm{~cm}^{-2}(150 \mathrm{~W}$, Newport 94011A LCS-100). The samples on FTO substrates were firstly prepared by a typical electrophoretic deposition method. For details, $25 \mathrm{ml}$ acetone solution containing $20 \mathrm{mg}$ sample and $40 \mathrm{mg}$ iodine was used as the electrophoresis solution. The experimental setup consists of two pieces of FTO that serve as the anodic and cathodic electrodes, respectively. The FTO substrates were immersed in the above solution in parallel with a distance of $1 \mathrm{~cm}$, which were kept in the solution for $5 \mathrm{~min}$ at a $10 \mathrm{~V}$ bias under the potentiostat control. After being calcined for $2 \mathrm{~h}$ in a vacuum oven at $100{ }^{\circ} \mathrm{C}$, a uniform film was firmly coated on the FTO substrates. Samples on FTO substrates were directly used as the working electrode, with a Pt wire and an $\mathrm{Ag} / \mathrm{AgCl}(\mathrm{KCl}$ saturated) electrode as counter and reference electrodes respectively. All the samples were illuminated through the sample side (front-side illumination). The photoelectrochemical performance was recorded in $0.1 \mathrm{M}$ $\mathrm{Na}_{2} \mathrm{SO}_{4}$ electrolyte with $0.1 \mathrm{mM}$ benzylamine. Mott-Schottky plots were derived from impedance-potential tests conducted at a frequency of $1 \mathrm{kHz}$ in dark. IMPS spectra were recorded by the Zahner Zennium C-IMPS system.

\section{Data availability}

All data supporting the findings in the article as well as the Supplementary Information files are available from the corresponding authors on reasonable request.

Received: 8 September 2020; Accepted: 3 March 2021; Published online: 01 April 2021

\section{References}

1. Shiraishi, Y. et al. Resorcinol-formaldehyde resins as metal-free semiconductor photocatalysts for solar-to-hydrogen peroxide energy conversion. Nat. Mater. 18, 985-993 (2019).

2. Chen, S., Takata, T. \& Domen, K. Particulate photocatalysts for overall water splitting. Nat. Rev. Mater. 2, 1-17 (2017).

3. Kofuji, Y. et al. Hydrogen peroxide production on a carbon nitride-boron nitride-reduced graphene oxide hybrid photocatalyst under visible light. ChemCatChem 10, 2070-2077 (2018). 
4. Hou, H., Zeng, X. \& Zhang, X. Production of hydrogen peroxide by photocatalytic processes. Angew. Chem. Int. Ed. 59, 2-23 (2020).

5. Fan, W. et al. Efficient hydrogen peroxide synthesis by metal-free polyterthiophene via photoelectrocatalytic dioxygen reduction. Energy Environ. Sci. 13, 238-245 (2020).

6. Hennessey, S. \& Farras, P. Production of solar chemicals: gaining selectivity with hybrid molecule/semiconductor assemblies. Chem. Commun. 54 6662-6680 (2018).

7. Teranishi, M., Naya, S.-i \& Tada, H. In situ liquid phase synthesis of hydrogen peroxide from molecular oxygen using gold nanoparticle-loaded titanium (IV) dioxide photocatalyst. J. Am. Chem. Soc. 132, 7850-7851 (2010).

8. Kato, S., Jung, J., Suenobu, T. \& Fukuzumi, S. Production of hydrogen peroxide as a sustainable solar fuel from water and dioxygen. Energy Environ. Sci. 6, 3756-3764 (2013).

9. Moon, G.-h, Kim, W., Bokare, A. D., Sung, N.-e \& Choi, W. Solar production of $\mathrm{H}_{2} \mathrm{O}_{2}$ on reduced graphene oxide- $\mathrm{TiO}_{2}$ hybrid photocatalysts consisting of earth-abundant elements only. Energy Environ. Sci. 7, 4023-4028 (2014).

10. Isaka, Y., Oyama, K., Yamada, Y., Suenobu, T. \& Fukuzumi, S. Photocatalytic production of hydrogen peroxide from water and dioxygen using cyanobridged polynuclear transition metal complexes as water oxidation catalysts. Catal. Sci. Technol. 6, 681-684 (2016).

11. Kim, H.-i, Kwon, O. S., Kim, S., Choi, W. \& Kim, J.-H. Harnessing low energy photons $(635 \mathrm{~nm})$ for the production of $\mathrm{H}_{2} \mathrm{O}_{2}$ using upconversion nanohybrid photocatalysts. Energy Environ. Sci. 9, 1063-1073 (2016).

12. Wei, Z. et al. Efficient visible-light-driven selective oxygen reduction to hydrogen peroxide by oxygen-enriched graphitic carbon nitride polymers. Energy Environ. Sci. 11, 2581-2589 (2018).

13. Shiraishi, Y. et al. Selective hydrogen peroxide formation by titanium dioxide photocatalysis with benzylic alcohols and molecular oxygen in water. ACS Catal. 3, 2222-2227 (2013).

14. Huang, Y., Chong, X., Liu, C., Liang, Y. \& Zhang, B. Boosting hydrogen production by anodic oxidation of primary amines over a NiSe nanorod electrode. Angew. Chem. Int. Ed. 57, 13163-13166 (2018).

15. Martin, A. \& Kalevaru, V. N. Heterogeneously catalyzed ammoxidation: a valuable tool for one-step synthesis of nitriles. ChemCatChem 2, 1504-1522 (2010).

16. Jagadeesh, R. V., Junge, H. \& Beller, M. Green synthesis of nitriles using nonnoble metal oxides-based nanocatalysts. Nat. Commun. 5, 1-8 (2014).

17. Łuczak, T. Electrochemical behaviour of benzylamine, 2-phenylethylamine and 4-hydroxyphenylethylamine at gold. A comparative study. J. Appl. Electrochem. 38, 43-50 (2007).

18. Fleming, F. F., Yao, L., Ravikumar, P., Funk, L. \& Shook, B. C. Nitrilecontaining pharmaceuticals: efficacious roles of the nitrile pharmacophore. J. Med. Chem. 53, 7902-7917 (2010).

19. Wang, T. \& Jiao, N. Direct approaches to nitriles via highly efficient nitrogenation strategy through $\mathrm{C}-\mathrm{H}$ or $\mathrm{C}-\mathrm{C}$ bond Cleavage. Acc. Chem. Res. 47, 1137-1145 (2014).

20. Yan, G., Zhang, Y. \& Wang, J. Recent advances in the synthesis of aryl nitrile compounds. Adv. Synth. Catal. 359, 4068-4105 (2017).

21. Liu, R. Y., Bae, M. \& Buchwald, S. L. Mechanistic insight facilitates discovery of a mild and efficient copper-catalyzed dehydration of primary amides to nitriles using hydrosilanes. J. Am. Chem. Soc. 140, 1627-1631 (2018).

22. Feldhues, U. Oxidation of primary aliphatic amines to nitriles at the nickel hydroxide electrode. Synthesis 2, 145-146 (1982).

23. Semmelhack, M. F. \& Schmid, C. R. Nitroxyl-mediated electro-oxidation of amines to nitriles and carbonyl compounds. J. Am. Chem. Soc. 105, 6732-6734 (1983).

24. Shono, T., Matsumura, Y. \& Inoue, K. Electroorganic chemistry. 87. Indirect electrooxidation of amines to nitriles using halogen ions as mediators. J. Am. Chem. Soc. 106, 6075-6076 (1984).

25. Tseng, K.-N. T., Rizzi, A. M. \& Szymczak, N. K. Oxidant-free conversion of primary amines to nitriles. J. Am. Chem. Soc. 135, 16352-16355 (2013).

26. Lambert, K. M. et al. Metal-free oxidation of primary amines to nitriles through coupled catalytic cycles. Chem. Eur. J. 22, 5156-5159 (2016).

27. Lambert, K. M. et al. Catalytic, metal-free oxidation of primary amines to nitriles. Org. Synth. 95, 60-79 (2018).

28. Dutta, I. et al. Double dehydrogenation of primary amines to nitriles by a ruthenium complex featuring pyrazole functionality. J. Am. Chem. Soc. 140 8662-8666 (2018).

29. Ovoshchnikov, D. S., Donoeva, B. G. \& Golovko, V. B. Visible-light-driven aerobic oxidation of amines to nitriles over hydrous ruthenium oxide supported on $\mathrm{TiO}_{2}$. ACS Catal. 5, 34-38 (2015).

30. Tao, C. et al. Merging visible-light photoredox and copper catalysis in catalytic aerobic oxidation of amines to nitriles. Org. Biomol. Chem. 15, 328-332 (2017).

31. Zhu, P. et al. Photocatalytic selective aerobic oxidation of amines to nitriles over $\mathrm{Ru} / \gamma-\mathrm{Al}_{2} \mathrm{O}_{3}$ : the role of the support surface and the strong imine intermediate adsorption. Catal. Sci. Technol. 10, 440-449 (2020).
32. $\mathrm{Wu}, \mathrm{K}$. et al. Unusual lattice vibration characteristics in whiskers of the pseudo-one-dimensional titanium trisulfide $\mathrm{TiS}_{3}$. Nat. Commun. 7, 12952 (2016).

33. Ahammed, R. et al. $\mathrm{ZrS}_{3} / \mathrm{MS}_{2}$ and $\mathrm{ZrS}_{3} / \mathrm{MXY}(\mathrm{M} \mathrm{Mo}, \mathrm{W} ; \mathrm{X}, \mathrm{Y} \mathrm{S}, \mathrm{Se}, \mathrm{Te} ; \mathrm{X} \neq \mathrm{Y}$ ) type-II van der Waals hetero-bilayers: Prospective candidates in 2D excitonic solar cells. Appl. Surf. Sci. 499, 143894 (2020).

34. Yi, H. et al. The electronic band structure of quasi-one-dimensional van der Waals semiconductors: the effective hole mass of $\mathrm{ZrS}_{3}$ compared to $\mathrm{TiS}_{3} . J$. Phys. Condens. Matter 32, 29LT01 (2020).

35. Wang, X. et al. Highly polarized photoelectrical response in $\mathrm{vdW} \mathrm{ZrS}_{3}$ nanoribbons. Adv. Electron. Mater. 5, 1900419 (2019).

36. Tao, Y. R., Wu, X. C. \& Xiong, W. W. Flexible visible-light photodetectors with broad photoresponse based on $\mathrm{ZrS}_{3}$ nanobelt films. Small 10, 4905-4911 (2014).

37. Flores, E., Ares, J. R., Ferrer, I. J. \& Sánchez, C. Synthesis and characterization of a family of layered trichalcogenides for assisted hydrogen photogeneration. Phys. Status Solidi Rapid Res. Lett. 10, 802-806 (2016).

38. Yuan, Y. et al. Zirconium nitride catalysts surpass platinum for oxygen reduction. Nat. Mater. 19, 282-286 (2020).

39. Endo, K., Ihara, H., Watanabe, K. \& Gonda, S. I. XPS Study of onedimensional compounds - TIS $_{3}$. J. Solid State Chem. 44, 268-272 (1982),

40. Tian, Z. et al. Enhanced charge carrier lifetime of $\mathrm{TiS}_{3}$ photoanode by introduction of $\mathrm{S}_{2}{ }^{2-}$ vacancies for efficient photoelectrochemical hydrogen evolution. Adv. Funct. Mater. 30, 2001286 (2020).

41. Wei, Y. Q., Zhou, Z. H. \& Long, R. Defects slow down nonradiative electronhole recombination in $\mathrm{TiS}_{3}$ nanoribbons: a time-domain $\mathrm{Ab}$ initio study. J. Phys. Chem. Lett. 8, 4522-4529 (2017).

42. Tian, Z. et al. Hydrogen plasma reduced black $\mathrm{TiO}_{2} \mathrm{~B}$ nanowires for enhanced photoelectrochemical water-splitting. J. Power Sources 325, 697-705 (2016).

43. Tian, Z. et al. Highly conductive cable-like bicomponent titania photoanode approaching limitation of electron and hole collection. Adv. Funct. Mater. 28, 1803328 (2018)

44. Tian, Z. et al. Novel black $\mathrm{BiVO}_{4} / \mathrm{TiO}_{2-\mathrm{x}}$ photoanode with enhanced photon absorption and charge separation for efficient and stable solar water splitting. Adv. Energy Mater. 9, 1901287 (2019).

45. Zhang, K. et al. Overcoming charge collection limitation at solid/liquid interface by a controllable crystal deficient overlayer. Adv. Energy Mater. 7, 1600923 (2017).

46. Li, L. et al. Electrical transport and high-performance photoconductivity in individual $\mathrm{ZrS}_{2}$ nanobelts. Adv. Mater. 22, 4151-4156 (2010).

47. Kanatzidis, M. \& Sutorik, A. (Karlin, K. D., Ed, 1995).

48. Xu, J., Tian, Z., Yin, G., Lin, T. \& Huang, F. Controllable reduced black titania with enhanced photoelectrochemical water splitting performance. Dalton Trans. 46, 1047- (2017)

49. Burrard-Lucas, M. et al. Enhancement of the superconducting transition temperature of FeSe by intercalation of a molecular spacer layer. Nat. Mater. 12, 15-19 (2013).

50. Hatakeda, T., Noji, T., Kawamata, T., Kato, M. \& Koike, Y. New Liethylenediamine-intercalated superconductor $\mathrm{Li}_{\mathrm{x}}\left(\mathrm{C}_{2} \mathrm{H}_{8} \mathrm{~N}_{2}\right)_{\mathrm{y}} \mathrm{Fe}_{2-\mathrm{z}} \mathrm{Se}_{2}$ with $\mathrm{Tc}=$ 45 K. J. Phys. Soc. Jpn. 82, 123705 (2013).

51. Scheidt, E.-W. et al. Superconductivity at Tc $=44 \mathrm{~K}_{\text {in }} \mathrm{Li}_{\mathrm{x}} \mathrm{Fe}_{2} \mathrm{Se}_{2}\left(\mathrm{NH}_{3}\right)_{\mathrm{y}}$. Eur Phys. J. E Soft Matter 85, 1-5 (2012).

52. Yin, G. et al. Hydrogenated blue titania for efficient solar to chemical conversions: preparation, characterization, and reaction mechanism of $\mathrm{CO}_{2}$ reduction. ACS Catal. 8, 1009-1017 (2018).

53. Resasco, J. et al. $\mathrm{TiO}_{2} / \mathrm{BiVO}_{4}$ nanowire heterostructure photoanodes based on type II band alignment. ACS Cent. Sci. 2, 80-88 (2016).

54. Xu, Y. \& Schoonen, M. A. The absolute energy positions of conduction and valence bands of selected semiconducting minerals. Am. Mineral. 85, 543-556 (2000).

55. Wang, Q. et al. Oxysulfide photocatalyst for visible-light-driven overall water splitting. Nat. Mater. 18, 827-832 (2019).

56. Liu, H., Xu, C., Li, D. \& Jiang, H. L. Photocatalytic hydrogen production coupled with selective benzylamine oxidation over MOF composites. Angew. Chem. Int. Ed. Engl. 57, 5379-5383 (2018).

57. Jellinek, F., Pollak, R. \& Shafer, M. X-ray photoelectron spectra and electronic structure of zirconium trisulfide and triselenide. Mater. Res. Bull. 9, 845-856 (1974).

58. Wang, X. et al. Single-atom vacancy defect to trigger high-efficiency hydrogen evolution of $\mathrm{MoS}_{2}$. J. Am. Chem. Soc. 142, 4298-4308 (2020).

59. Li, H. et al. Corrigendum: activating and optimizing $\mathrm{MoS}_{2}$ basal planes for hydrogen evolution through the formation of strained sulphur vacancies. Nat. Mater. 15, 48-53 (2016).

60. Sun, X. et al. Enhanced superoxide generation on defective surfaces for selective photooxidation. J. Am. Chem. Soc. 141, 3797-3801 (2019).

61. $\mathrm{Li}, \mathrm{X}$. et al. Selective visible-light-driven photocatalytic $\mathrm{CO}_{2}$ reduction to $\mathrm{CH}_{4}$ ediated by atomically thin $\mathrm{CuIn}_{5} \mathrm{~S}_{8}$ layers. Nat. Energy 4, 690-699 (2019). 
62. Song, H., Wei, L., Chen, C., Wen, C. \& Han, F. Photocatalytic production of $\mathrm{H}_{2} \mathrm{O}_{2}$ and its in situ utilization over atomic-scale Au modified $\mathrm{MoS}_{2}$ nanosheets. J. Catal. 376, 198-208 (2019).

63. Lei, J. et al. Robust photocatalytic $\mathrm{H}_{2} \mathrm{O}_{2}$ production over inverse opal g- $\mathrm{C}_{3} \mathrm{~N}_{4}$ with carbon vacancy under visible light. ACS Sustain. Chem. Eng. 7, 16467-16473 (2019).

64. Credgington, D. \& Durrant, J. R. Insights from transient optoelectronic analyses on the open-circuit voltage of organic solar cells. J. Phys. Chem. Lett. 3, 1465-1478 (2012).

\section{Acknowledgements}

The authors acknowledge the financial support from Singapore National Research Foundation under the grant of NRF2017NRF-NSFC001-007, NUS Flagship Green Energy Programme, Fundamental Research Foundation of Shenzhen (No. JCYJ20190808152607389 and No. JCYJ20170817100405375), China Postdoctoral Science Foundation (2020M672794), and Shenzhen Peacock Plan (No. KQTD2016053112042971)

\section{Author contributions}

T.Z., H.C., L.H. and C.W. conceived and designed the experiments. T.Z., Z.Y., D.W., L.X., W.Y. and Z.Y. performed the experiments. T.Z., L.X. and H.Z. analyzed the data. T.Z, S.Y., and P.X. wrote the manuscript. All authors discussed the results and commented on the manuscript.

\section{Competing interests}

The authors declare no competing interests.

\section{Additional information}

Supplementary information The online version contains supplementary material available at https://doi.org/10.1038/s41467-021-22394-8.

Correspondence and requests for materials should be addressed to C.H. or W.C.

Peer review information Nature Communications thanks Pau Farràs, Vladimir B. Golovko, and Lei Han for their contributions to the pee review of this work. Peer review reports are available.

Reprints and permission information is available at http://www.nature.com/reprints

Publisher's note Springer Nature remains neutral with regard to jurisdictional claims in published maps and institutional affiliations.

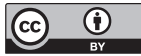

Open Access This article is licensed under a Creative Commons Attribution 4.0 International License, which permits use, sharing, adaptation, distribution and reproduction in any medium or format, as long as you give appropriate credit to the original author(s) and the source, provide a link to the Creative Commons license, and indicate if changes were made. The images or other third party material in this article are included in the article's Creative Commons license, unless indicated otherwise in a credit line to the material. If material is not included in the article's Creative Commons license and your intended use is not permitted by statutory regulation or exceeds the permitted use, you will need to obtain permission directly from the copyright holder. To view a copy of this license, visit http://creativecommons.org/ licenses/by/4.0/.

(C) The Author(s) 2021 